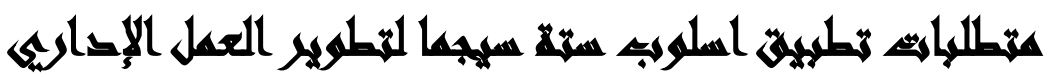

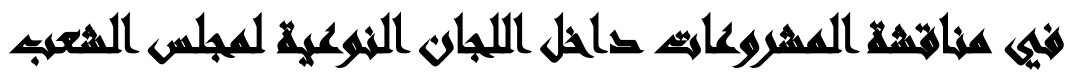

[rฯ]

\author{
نزار كمال محمد نصري المحلاوي(')- علي طلبه(ץ)- محمد وهدان(ץ)
}

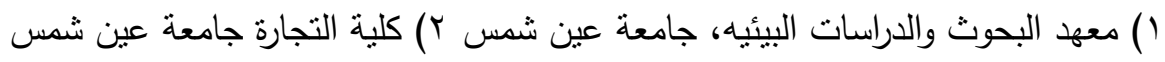

\section{المستحلت}

عرفت البشرية العديد من نظم الجودة في الإدارة والتي ارتبطت بالتطور الحضاري

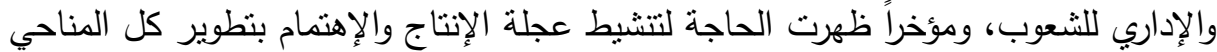

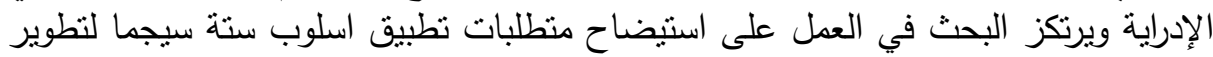

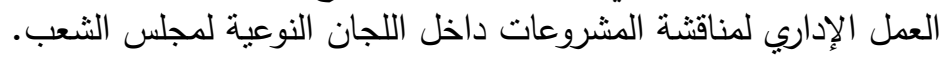
هدفت الاراسة للتعرف على أبعاد جودة العملية الإدارية داخل اللجانة الإنية النوعية من خلاد

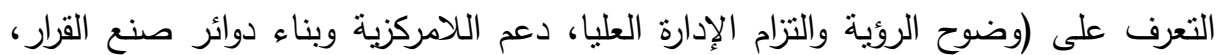

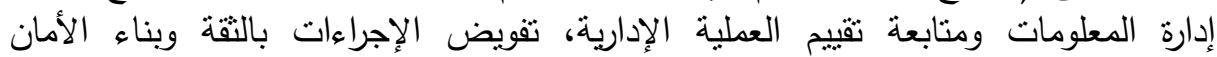

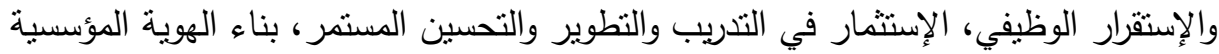

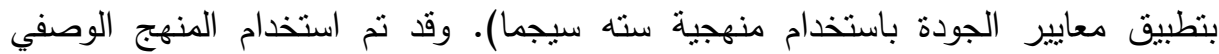

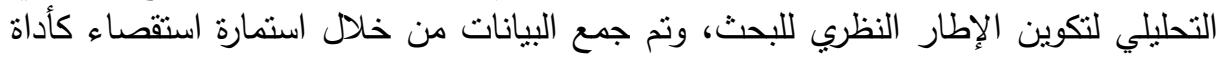

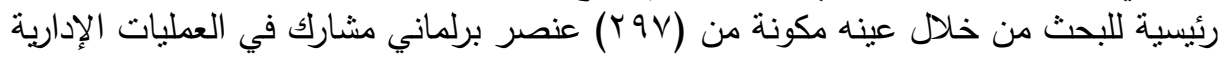
للجان النوعية بمجلس الثعب، وقد أظهرت النتائج ضعف (بنداء الهن الهوية المؤسسية - الخطوات الإدارية لدعم اللادركزية وبناء دوائر صنع القرار) ولذلك أوصت التهاء الدارسة بتأهيل الموارد

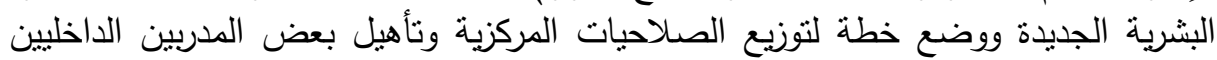
وانثاء جائزة وطنية بإسم مجلس الثعب وانشاء جائزة داخلية لحفز العاملين بالمجلس.

\section{Marall}

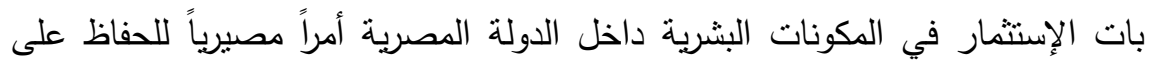

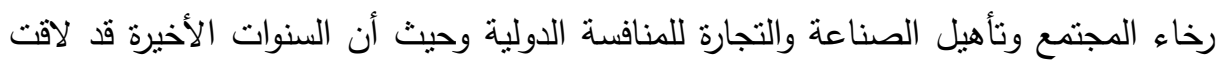

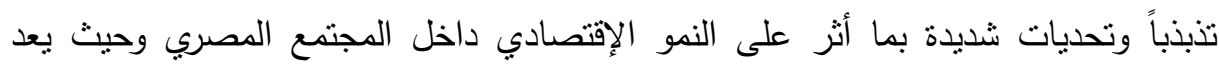
العنصر البشري المحرك الأول لعملية التتمية وهو المستقيد الأساسي منها فقد رأى التهي الباحث

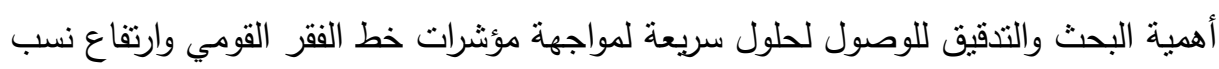

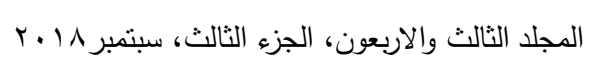


التضخم وغيرها من المؤشرات خلال السنوات الخمس الأخيرة بداية من عام r ا ـ ب وحتى عام

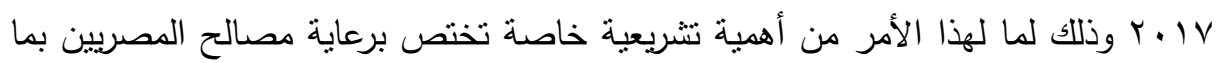

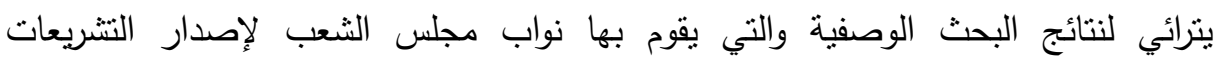

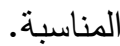
جدول رقم(1): خط الفقر القومي / المصدر /الجهاز المركزي للتعبئة العامة والأحصاء

\begin{tabular}{|c|c|c|}
\hline & خط الفقر القومي & المؤشر \\
\hline البيان & القيمة & الملحوظة \\
\hline$r_{.} \| 1 / r_{.1}$. & $r, 1$ & \\
\hline$r \cdot I T / r \cdot I r$ & $r, 9$ & \\
\hline$r .10$ & 0,1 & \\
\hline
\end{tabular}

إن زيادة معدل خط الفقر القومي وكذلك ارتفاع معدل التضخم خلال السنوات الأخيرة قد يكون متزامناً مع بداية العمل على تطوير طريقة البحث والتنقيق والتنفيذ والتشريع للمشروعات المقترحة داخل البرلمان من النواب بعرضها ومناقثتها باستخدام معايير الستة سيجما سيفيد الإدارة البرلمانية بتوحيد لغة النقد والعرض والتطوير وهو مما سيساهم في تسهيل الحكم على لتى المشروعات وكذلك المقارنة بين الأولويات واختيار الإختبار الأنسب من بين عدة مشروعات قد تكون مقترحة. جدول(ץ): (صورة) معدل التضخم السنوي للجمهورية / الجهاز المركزي للتعبئة العامة والأحصاء

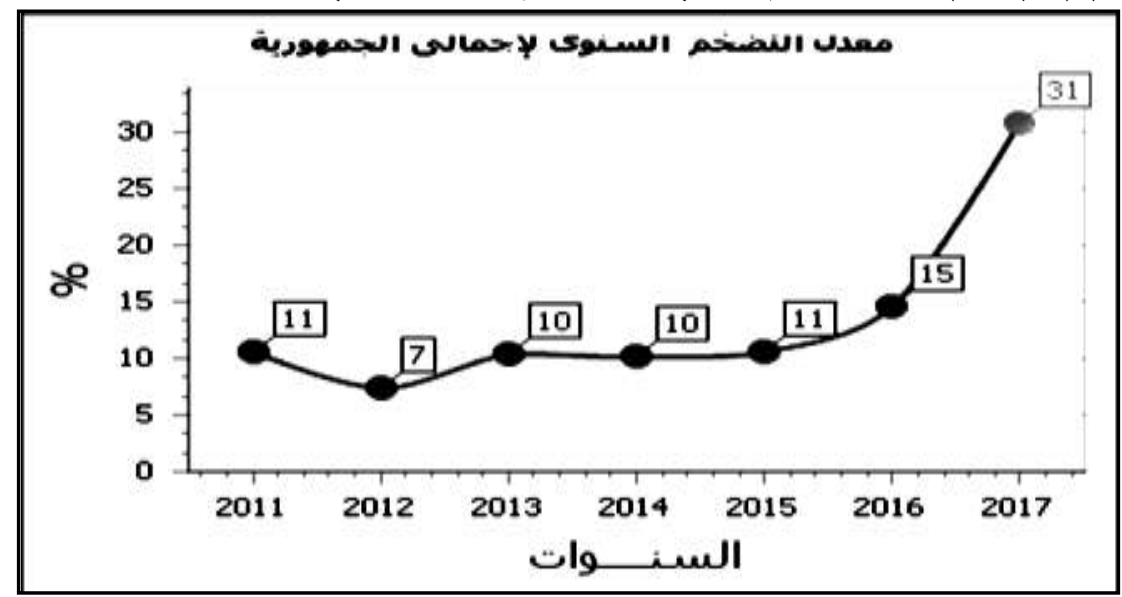


وفي سبيل سعي الدول لتحقيق التوازن الحقيقي بين معدلات التضخم والإستثمار في

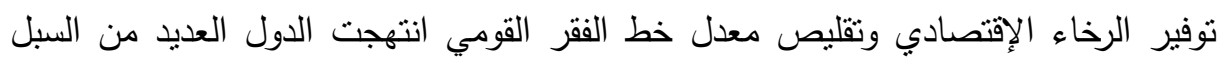
الإدارية فقد عرفت البشرية في العصر الحديث العديد من نظم الجودة في الإدارة والتي مأي

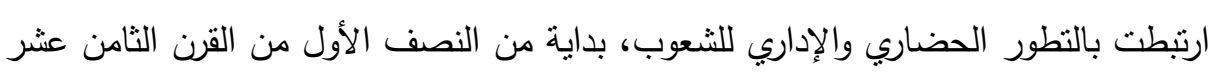

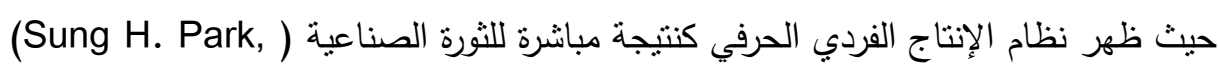

في بداية القرن العشرين كانت عمليات التسويق سبباً للمنافسة فأصبح من المكن الحصول على درجات مختلفة من الجودة وكذلك درجات مختلفة من الأسعار ولهذا كان الوفاء بأساسيات الجودة معياراً أساسياً يتم من خلاله المقارنه بين المنتجات وكان دودات معياراً حيوياً

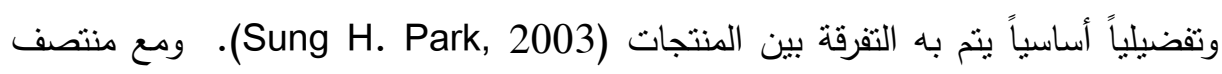

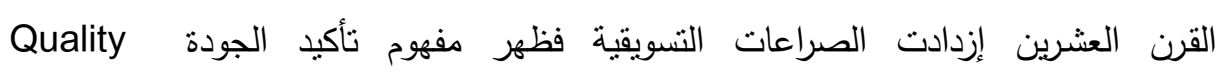
Assurance الثركات الصناعية الكبرى في التغول والتركيز على توسيع الإنتاج لأقصى درجة مدكنه فظهر

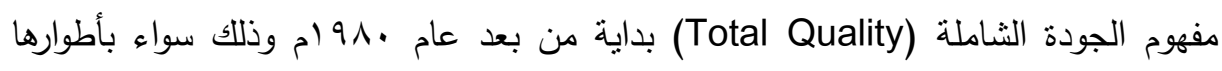
الأولى أو الثانية كان هدفها هو الوصول بالعملية الإدارية لإتقان العمليات المتعلقة بالإنتاج

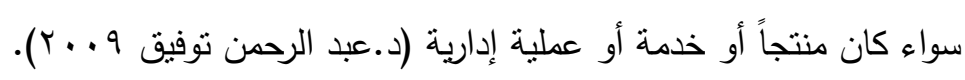

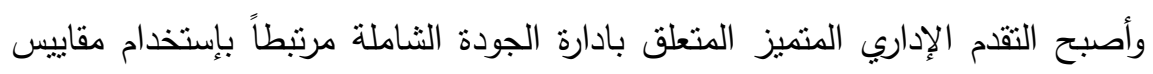

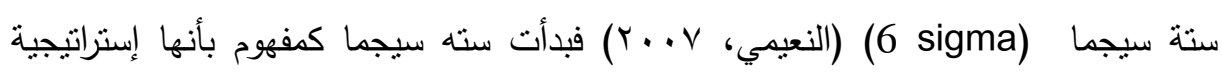

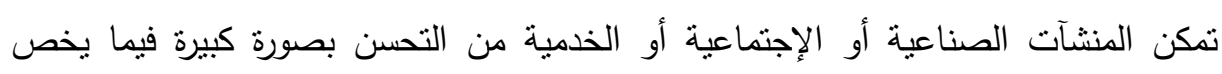
عملياتها الأساسية وهيكلها من خلال تصميم ومراقبة أنثطة الأعمال اليومية بحيث ينم تقليل التيل الفاقد واستهلاك المصادر (الوقت - الطاقات الذهنية - الطاقات المادية) وفي نفس الوقت الون تلبية احتياجات العميل وتحقيق القناعة لديه، ويدل مبدأ سته سيجما على أن المنشأة تقدم

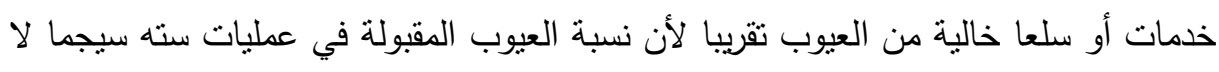

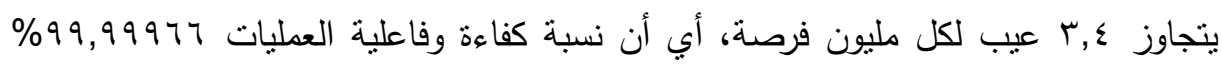
.(Stephan Lunau (Eta.), 2009)

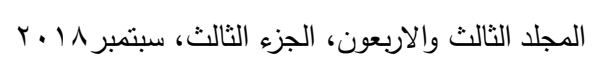


خلاصة الأمر أن فكرة (6 Sigma) تكمن في أنه إذا كانت المنثأة قادرة على قياس

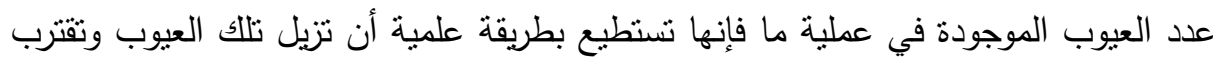
من نقطة الخلو من العيوب ودرجة إنعدام الأخطاء.

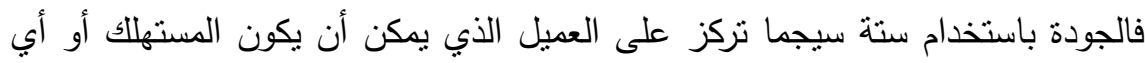

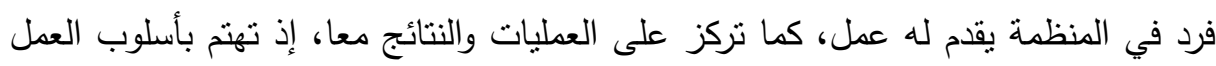

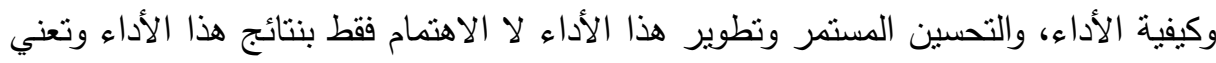
تتمية الموارد البشرية وتطوير كفاءتها ولا تعني اكتثاف الأخطاء بل منع وقوعها فهي تركز على أداء الأعمال الأساسية والمساعدة بالطريقة الصحيحة ومن أول مرة، وتعني كفاءة نظام المعلومات، وكفاءة التغذية المرتدة، فقد تعدى مفهوم الجودة جودة المنتج ذاته ليشمل أيضا:

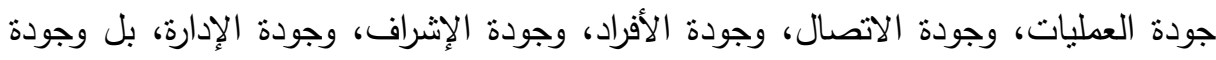

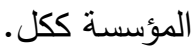

\section{ميف2 التواسمة}

من خلال متابعة ومشاهدة العديد من المناقتنات ودراسة المشروعات وطلبات الإحاطة داخل اللجان النوعية بمجلس الشعب المصري ومن خلال قراءات الباحثون التحليلية لطبيعة أحداث التحول الديموقراطي واختلاف الإتجاهات السياسية والأيدولوجية تحت قبة فئ مجلس الثعب، وكذلك بعد استمرار تعليق انعقاد مجلس الشعب المصري ولمدة تزيد عن ثلاث سنوات تقريباً منذ حل المجلس بموجب حكم المحكمة الدستورية العليا عام با ـ ب وحتى عودة الإنعقاد

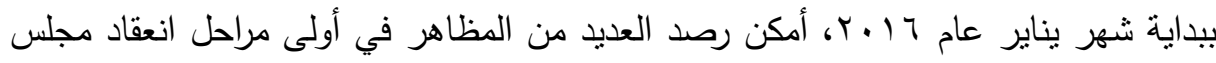
الثعب بعد نتكيله وهي التي ربما قد تعني وجود خلل ما في مفاهيم إدارة عمليات المناقتشات

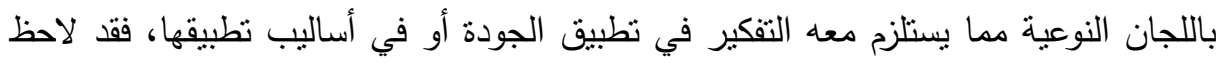
الباحثون ارتفاع معدل التضخم بققزات رقمية ونوعية كبيرة وكذلك ازداياد مؤشر خط الفقر

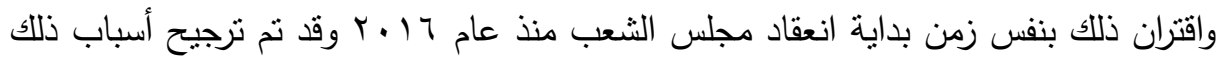
بسبب ظهور عدد من المظاهر يُرجعها الباحثون إلى انخفاض كفاءة أنشطة وأساليب وأدوات 
الجودة في عرض المشروعات ومناقثاتها ربما لأن تعارض الأيدولوجيات والمناهج السياسية هي الوسيط والمحرك الاول للمناقثات والإعتراضات وطلبات الأحاطة، وفي الحالات التي يتم

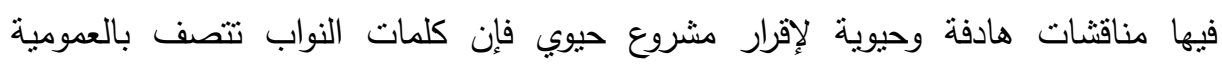

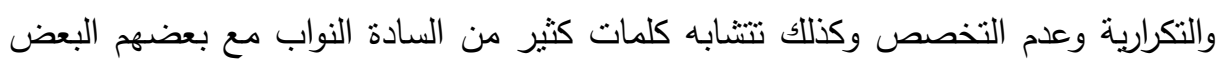
بما لا يعود بفائدة محددة إيجابية على المناقثات أو طلبات الأحاطة.

\section{أهمية الصوراسلا}

ا ـ تتبع أهمية الدراسة من كونها تتتاول كفاءة عمليات مناقثات اللجان النوعية بمجلس

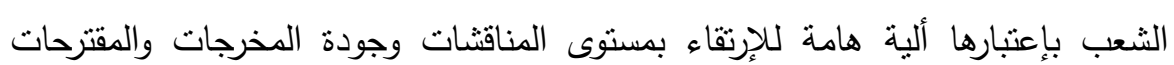

والقرارات النيابية.

r. تتضح أيضاً أهمية الدراسة من جانبين الجانب العملي وهو المتعلق باهمية دراسة برامج

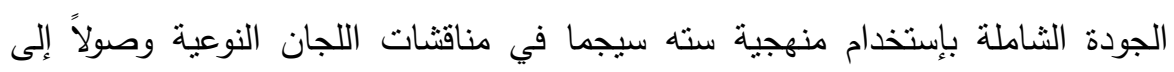

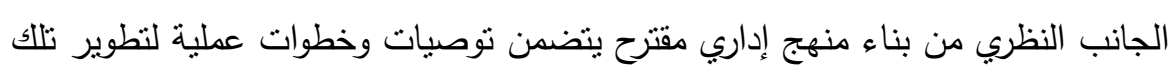

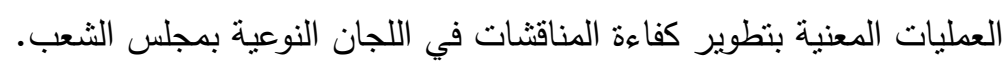

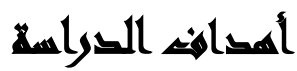

تهدف هذه الاراسة إلى معرفة منطلبات نطوير العمل الإداري داخل مناقثات اللجان النوعية بمجلس الثعب المصري وذلك من خلال التعرف إلى المزايا التي يحققها تطبيق إدارة الجودة الثاملة باستخدام معايير ستة سيجما على مستوى المنظمات المجتمعية والخدمية

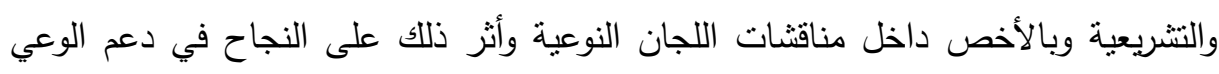
الإداري على المستوى القومي وانعكاسه في الإنجاز الإداري على المستوى العالمي.

\section{هزوخ التوراسة}

الفرض الرئيس: لا توجد علاقة معنوية بين تطبيق منهجية سته سيجما في مناقثة

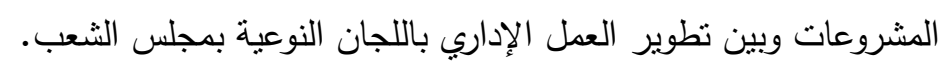




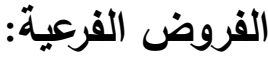

ا. لا توجد علاقة معنوية بين نوافر وضوح الروية والتزام الإدارة العليا وبين نطوير العمل الإداري باللجان النوعية بمجلس الثعب

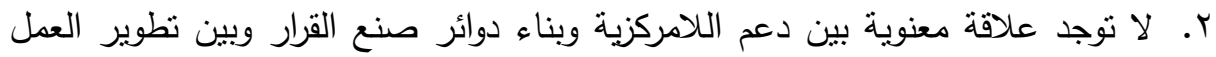

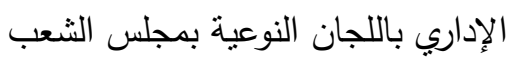

r. لا توجد علاقة معنوية بين إدارة نظم المعلومات ومتابعة تقييم العملية الإدارية وبين تطوير

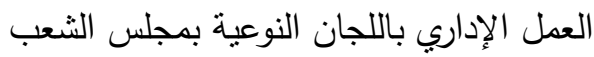
ع. لا توجد علاقة معنوية بين تفويض الإجراءات بالثقة وبناء الأمان والإسنقرار الوظيفي وبين تطوير العمل الإداري باللجان النوعية بمجلس الثعب

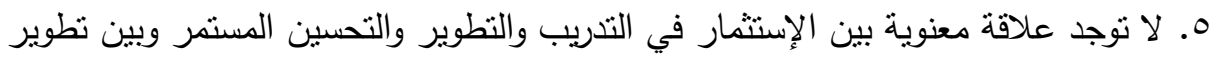
العمل الإداري باللجان النوعية بمجلس الثعب 7. لا توجد علاقة معنوية بين بناء الهوية المؤسسية بنطبيق معايير الجودة وبين تطوير العمل الإداري باللجان النوعية بمجلس الثعب لهب لهبه

\section{مسطلحاهي التراسها}

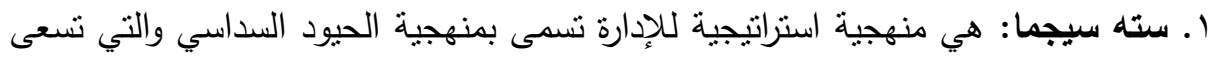
إلى وضع مراحل ادارية للنعامل مع أي عملية إدارية بهدف الوصول إلى تحقيق الجودة المتمثل في خفضل التكاليف وتقليل الوقت وزيادة الأرباح (النعيمي، V ... Y). r. اللجان النوعية: هي نوع من اللجان البرلمانية وهي المسئولة عن إنجاز العديد من المهام فتسمح اللجان للنواب بدراسة وفحص مشروعات القوانين والإشراف على البرامج الحكومية

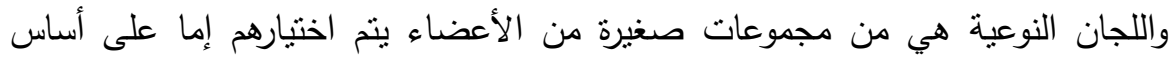

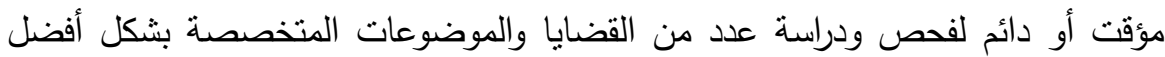

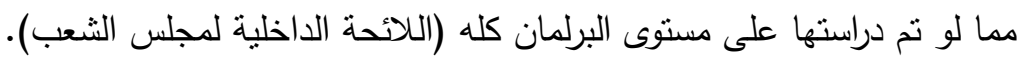




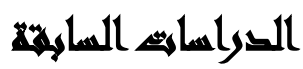

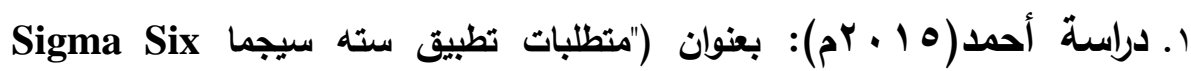

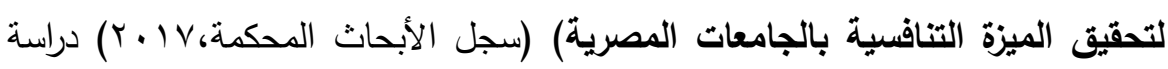
تطبيقية على بعض كليات جامعة جنوب الوادي".هدفت الدراسة إلى تحديد درجة نوافر

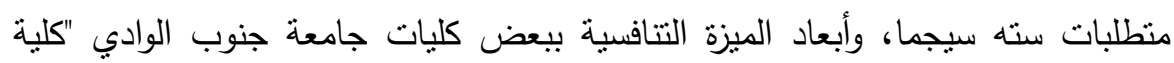
العلوم / الزراعة / الهندسة "، وكذلك المعوقات التي تاجه نواجه تطبيق اسلوب سته سيجما

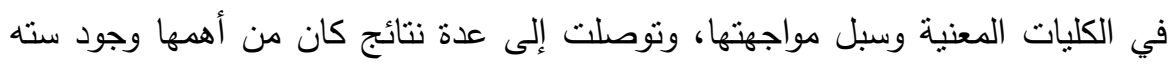

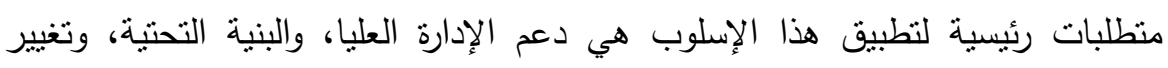

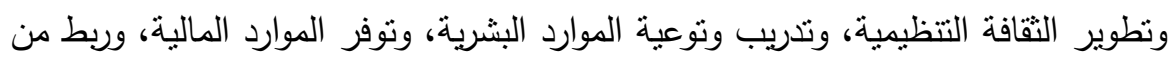

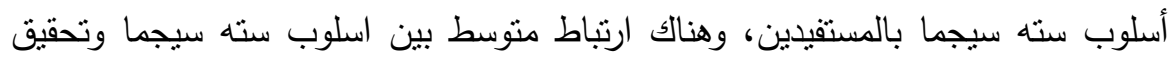

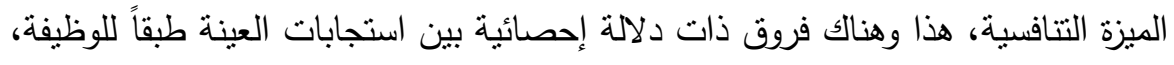

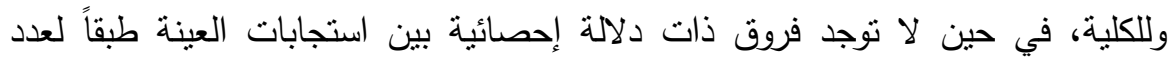
سنوات الخبرة.

r. دراسة الزيد(0 10 • Y م): بعنوان "المعايير الإحصائية لمنهجية ؟ سيجما في تحسين جودة التعليم العالي" .وهدفت الدراسة إلى وضع إطار فلسفي نظري لأسلوب السته سيجما، وتحديد الأساليب الإحصائية التي بنى عليها مع تطبيقها على مؤسسات التعليم العالي من خلال قياس مستوى مخرجات الجامعات، وتوصلت إلى وجود ضعف في في في لإنى

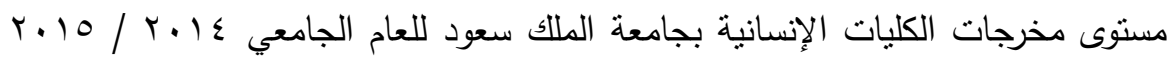

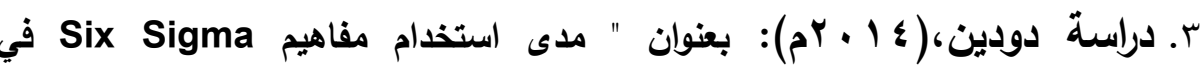
الجامعات الأردنية الحكومية والخاصة" ـ وقد هدفت الاراسة إلى تحديد مدى استخدام

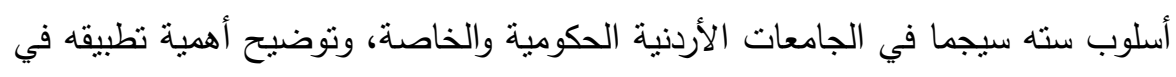
التحسين المستمر للعمليات والخدمات التعليمية، وكذلك معوقات تطبيقه في الجامعات الدذكورة، وتوصلت إلى حداثة هذا الأسلوب بالجامعات، وعدم وجود نموذج واضح لهذات ولئات

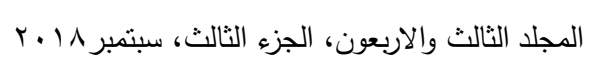


الأسلوب يمكن تطبيقه لغرض التحسين المستمر في العمليات والخدمات ، هذا بالإضافة إلى ضعف الموارد المالية والكفاءات البشرية.

ك. The Effect of Six Sigma بعنواسة (Hsia.2006) وق هدفت الدراسة إلى "Implementation on" Business Performance التعرف على أثز تطبيق ستة سيجما على أداء العاملين. وقد كان مجتمع الدراسة وعينته: قطاع الصناعة في تايوان، وهي عب شركة في عدة قطاعات كقطاع الاتصالات، الالكترونيات، السمعيات والمرئيات. وأدوات الدراسة: استبيان تم توزيعه على كل من حملة الأحزمة الخضراء بالإضافة إلى فئة الإدارة التنفيذية في الثركات. وكاتت أهم نتائج الاراسة: (أن تطبيق ستة سيجما له أثر إيجابي لتقليل التكاليف وتقليل معدلات الأخطاء، وجود علاقة إيجابية ين عملية النطبيق وبين نمو عوائد هذه الثركات، وجود علاقة مابين

$$
\text { ستة سيجما وبين رضا المستهلكين.) }
$$

Six Sigma Operating " دراسة (Swink \& Jacobs,2012) بعوان "performance impacts and contextual drivers of success" إلى تقييم الأثز التتغيلي المترتب عند تطبيق سيجما ستة. وقد كان مجتمع الدراسة

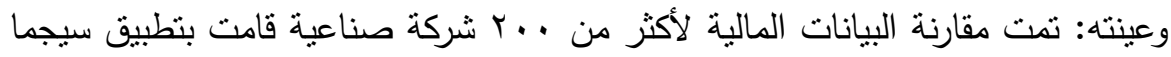
ستة بمثيلاتها ممن لم تقم بنطبيق سيجما سنة. بينما أدوات الدراسة استخدمت منهجية

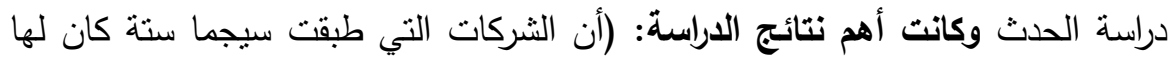

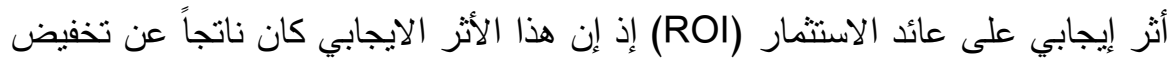

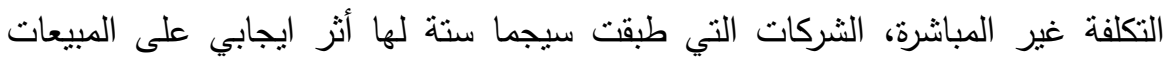

\section{الإطار المغظليه}

بناءً على ما سبق وبعد مراجعة الدراسات السابقة المتعلقة بنظم إدارة الجودة الثاملة باستخدام اسلوب سته سيجما وعلاقتها بجودة الاداء الإداري فقد رأى الباحثون أن دراسة موضوع هذا البحث يتطلب أن يُقسم إلى المقدمة الرئيسية ومنهجية الدراسة والدراسات السابقة

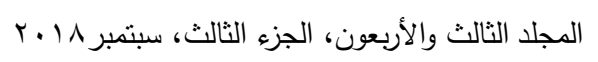


يليها ثلاثة فصول رئيسية تبدأ بدراسة مفهوم الجودة الثاملة (نثأة ونظور نظام إدارة الجودة)

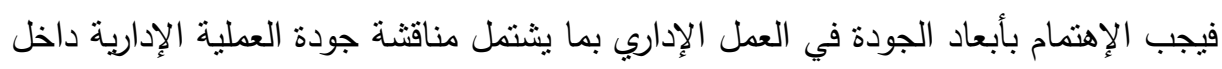

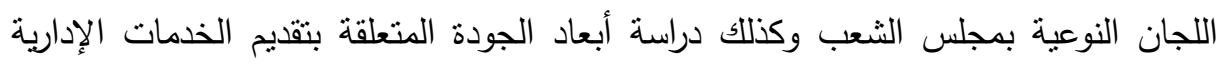
والنماذج المستخدمة في حل مشكلات الجودة الثناملة والمنهجيات الإدارية المختلفة لتطبيق الجودة الثاملة ( Total Quality) ومن ثم مناقثة بعض المشاكل التي نواجه إدارة الجودة الثاملة وخطوات عملية تحسين الجودة التي تشكل النموذج المناسب لمواجهة وحل المشكلات. وهو الأمر الذي يساهم في تحقيق الفاعلية في تطبيق مفهوم ادارة الجودة الثاملة

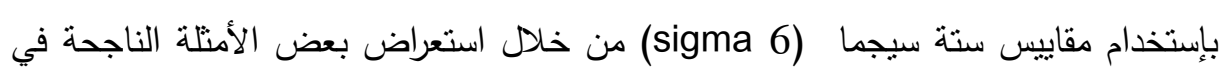

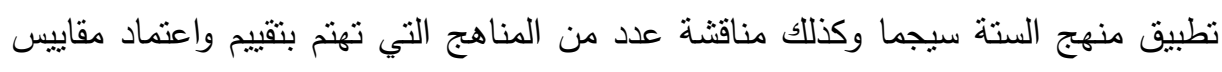

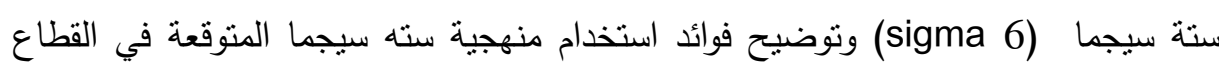
الإداري الحكومي.

فالبناء التتظيمي للستة سيجما من خلال تحديد بعض المستهدفات الخاصة بمنطلبات تطبيق سته سيجا وهي كالأتي: • المستهدف الأول: عناصر فريق عمل مشروعات ستة سيجما وقد ناقش البحث أولاً الحزام

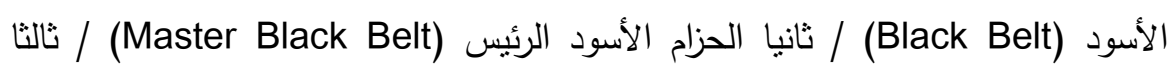

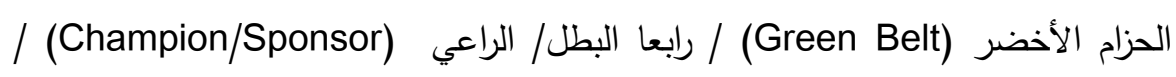

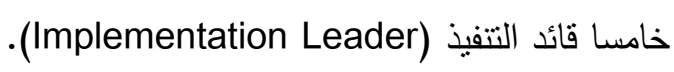
• المستهذف الثاني: أدوار فريق عمل الستة سيجما وهو المتعلق بنوضيح أدوار أفراد الحزام

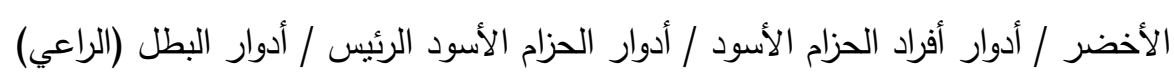

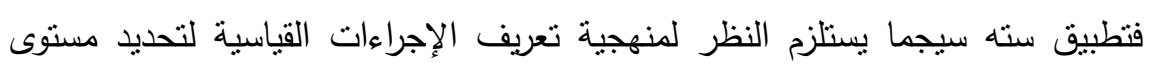

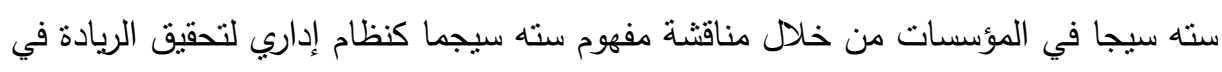

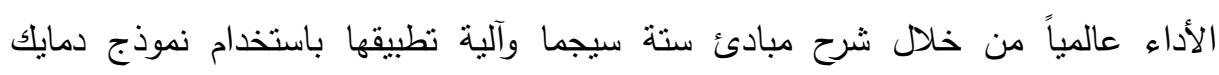
وكذلك عرض نموذج دمادف DMADV أو DFSS الذب في يساهم في تحديد

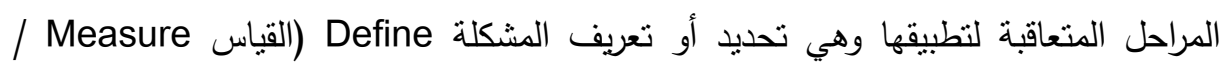

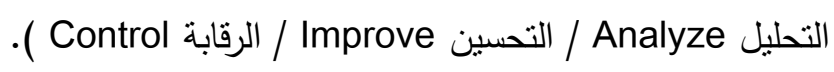

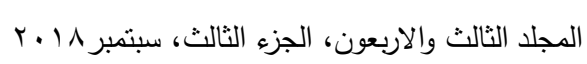


وقد ظهرت متطلبات تطبيق منهجية سته سيجما على العمل الإداري من خلال المعايير

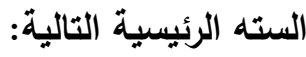

ا ـ المعيار الأول (وضوح الروية والتزام الإدارة العليا) r. المعيار الثاني (دعم اللامركزية وبناء دوائر صنع القرار) r. المعيار الثالث (إدارة المعلومات ومتابعة تقييم العملية الإدارية)

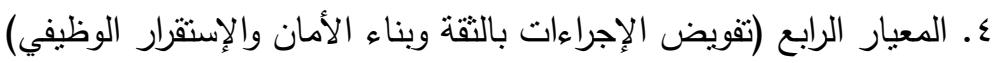
ه. المعيار الخامس ( الإستثمار في التدريب والتطوير والتحسين المستمر ) T. المعيار السادس (بناء الهوية المؤسية بتطبيق معايير الجودة، لسته سيجما) (المؤسسات البرلمانية) فعملية دراسة مواصفات النظام البرلماني والنظام النصف رئاسي

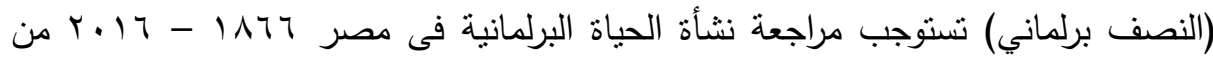
خلال دراسة المنهجية العامة لرسم السياسات البرلمانية بما تحتويه من إطار العمل وعمليات الرقابة البرلمانية التشريعية والتتفيذية وهو ما يرسم منهجية لتعريف كفاءة اللجان النوعية من

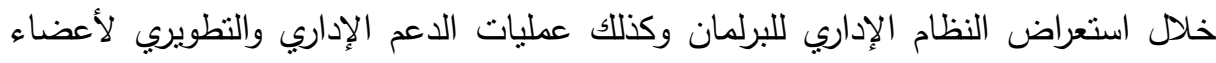
البرلمان، لأن تطوير العمل الإداري عادة ما يستلزم مراجعة الدروس المستفادة من تجارب لإب لهاب

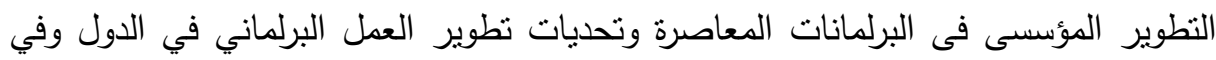
النهاية استدراك عمليات وفرص نطوير نظام اللجان النوعية بالبرلمان المصري من خلال استعراض الأنواع التخصصية للجان وعدد اللجان وطبيعة اجتماعاتها والتتسيق بينها وآلية عمل لجان الاستماع وما لها من صفات في فهم خصائص لجان الاستماع كآلية إدارية بما ولهاب لها من دور رقابى وهو مما استلزم من الباحث مناقتشة منهجية عمل اللجان النوعية من خلال المستلزمات التى تحتاجها اللجان النوعية والكيفية التى يمكن للجان تقديم المعاونة.

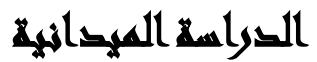

التعريف بمنهجية الدراسة: تتطور منهجية الدراسة من خلال استعراض النقاط التالية بالترتيب

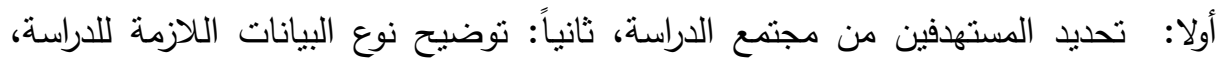

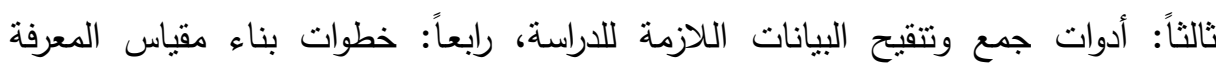
644

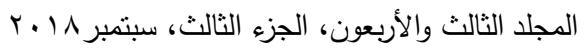


الإدارية، خامساً: اختبارات صدق وثبات مقياس المعرفة الإدارية، سادساً: تتفيذ الدراسة

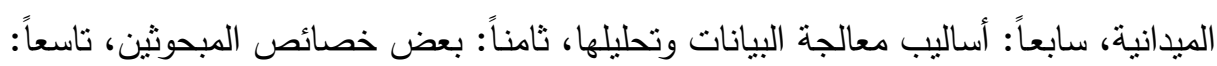
اختبار الفروض ونتائج نتغيل البيانات.

استنتاجات ومستخلصات الاراسة: تتبلور قراءة الإستتناجات التي تم التوصل إليها في مستخلص الدراسة ونتائجها من خلال النعليق على نتائج الإستقصاء الإداري وحتى كتابة الخاتمة بما تحتويه من الإقتراحات والتوصيات وفي النهاية استعرض البحث قائمة المراجع بما لإنها فيها المراجع العربية والأجنبية.

\section{الإيراعايت المنهجية للتصواسمة}

متغيرات الاراسة: تعتمد الدراسة على متغييرين رئيسيين هما:

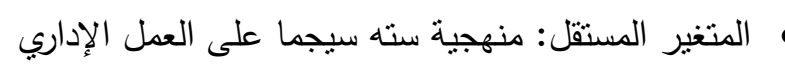

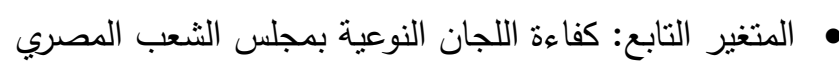
منهجية الدراسة: يعتمد هذا البحث على المنهج الوصفي التحليلي للوصول إلى الأهداف

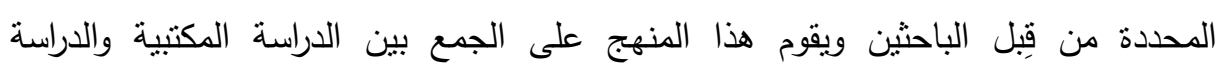
الميدانية. أ. الدراسة النظرية: حيث تم جمع المادة العلمية من خلال الإطلاع على الكتب والمراجع

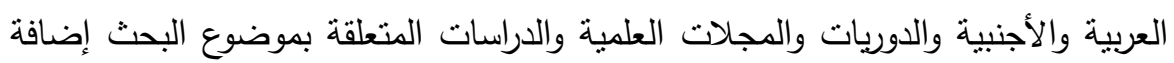
إلى المقالات العلمية المتخصصة الموجودة في الفضاء الإلكتروني. ب. الاراسة الميدانية: يتم اختبار صحة الفروض من خلال جمع البيانات والمعلومات اللازمة ذات الصلة بموضوع البحث من خلال تصميم قائمة استقصاء وتوزيعها على عينه البحث وإجراء المقابلة الثخصية والملاحظة المباشرة.

ت.حدود مكانية: يقتصر البحث على عدد تسع من اللجان النوعية بمجلس الثعب المصري ولئي

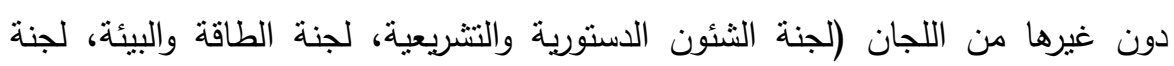

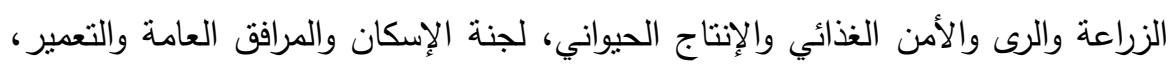


لجنة الثباب والرياضة، لجنة الثئون الصحية، لجنة النقل والمواصلات، لجنة التعليم

والبحث العلمي، لجنة الثنؤون الدينية والاجتماعية والأوقاف) وذلك لأهميتها.

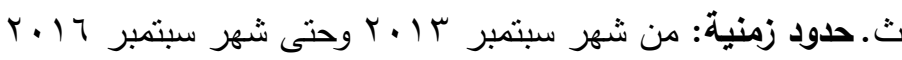

أداة الدراسة: استبيان للتحقق من فروض وأهداف الدراسة من خلال عدة محاور يحاول الباحثون من خلالها التحقق من الفروض.

أ. أدوات جمع البيانات اللازمة للاراسة: استخدمت ثناثة أدوات لجمع البيانات، وهي استمارة الإستقصاء كأداة سيكومترية رئيسية، ثم الملاحظة والمقابلة الثخصية كأداتين مساعدنين في تفسير نتائج الأداة الرئيسية.

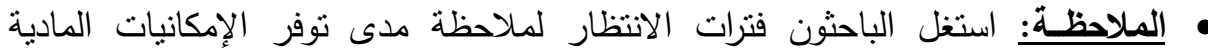

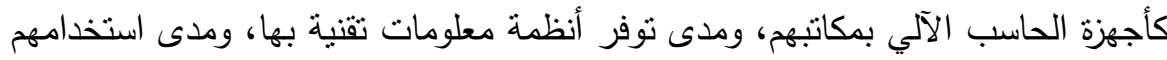
إياها، وملاحظة أية ظواهر أخرى تؤثر على كيفية الأداء، وقام الباحث باختزال ما يشاهده

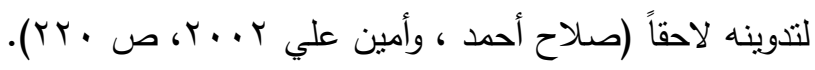

• المقابلة الثخصبـة: استخدم الباحث المقابلة الثخصية شبه المقنتة مع بعض المبحوثين

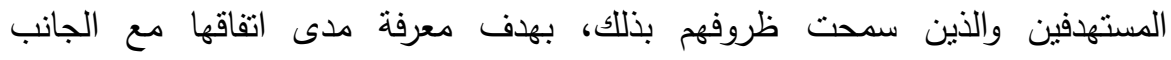

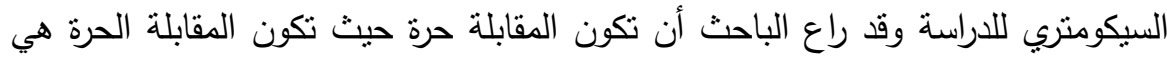
مقابلة غير مقيدة بنظام عرض الأسئلة حيث تقدم الأسئلة وفق ما يناسب الموقف، وليست انت

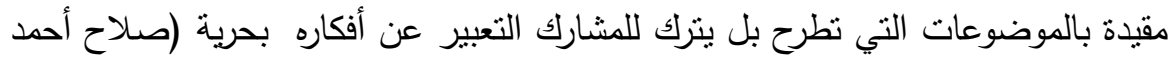

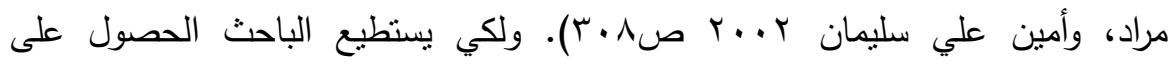
البيانات المطلوبة بأقل قدر من التوجيه للمبحوث، وبأكبر قدر من التلقائية. ولقد تم تحديد زمن المقابلة من 10 - 20 دقيقة مع الاحتفاظ بقدر من المرونة طبقا لمتطلبات الموقف.

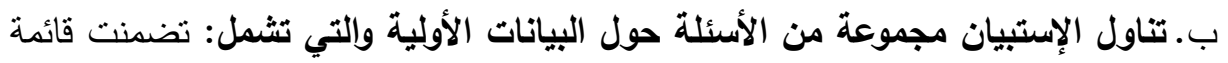
الإستقصاء على جزأين كما يلي: 
الجزء الأول: ويتعلق بالبيانات الديموغرافية للمبحوثين وهي بيانات عامة عن المبحوثين تتعلق بالمؤهل العلمي، والعمر، والجنس، وعدد سنوات الخبرة البرلمانية، ومقر اللجنه

$$
\text { الإنتخابية (وجه بحري، وجه قبلي). }
$$

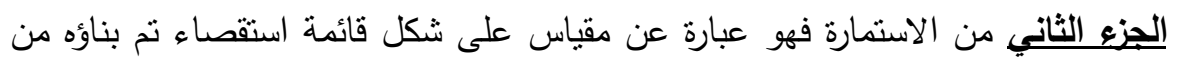

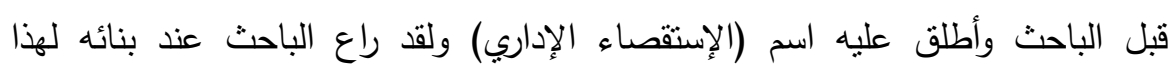
المقياس (الإستقصاء الإداري) الثروط الأولية في بناء المقاييس (صلاح أحمد مراد، وأمين الإداء

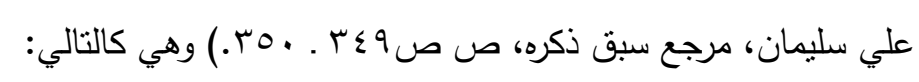

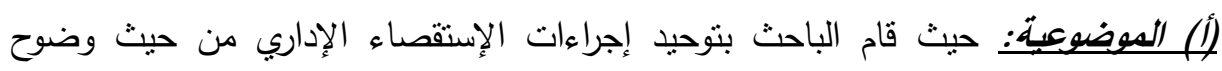
التعليمات، وتحديد زمن الإجابة، وطريقة التصحيح، فقد تمت صياغة تعليمات الإجابة

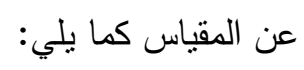

\} أمامك مجموعة من العبارات التي تعبر عن بعض الإجراءات الإدارية داخل اللجان

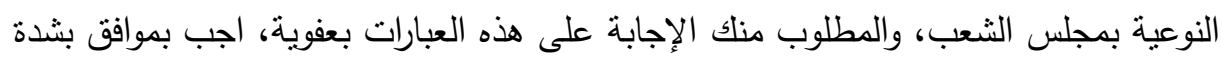

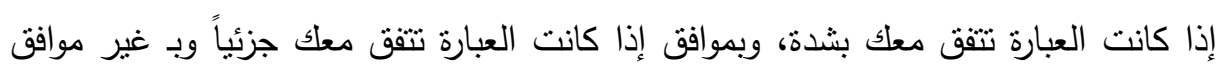
بثدة إذا كانت العبارة لا تتفق معك بشدة، وبغير موافق إذا كانت لا تتقق معك جزئئاً، وبـ

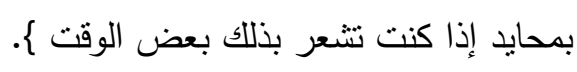

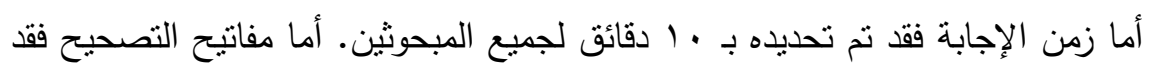

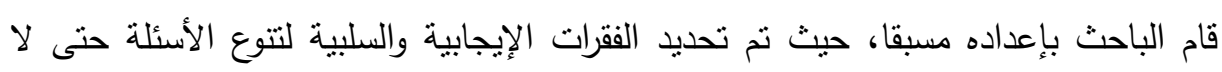

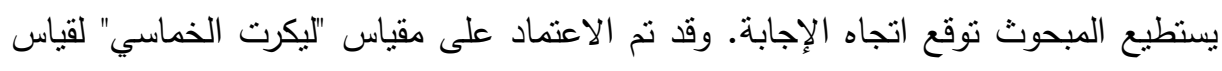

\begin{tabular}{|c|c|c|c|c|c|}
\hline غيثد موافق & غير موافق & محايد & موافق & بشَدة & الاستجابة \\
\hline 0 & $\bar{\varepsilon}$ & $\bar{\mu}$ & $\bar{T}$ & 1 & الدرجة \\
\hline
\end{tabular}

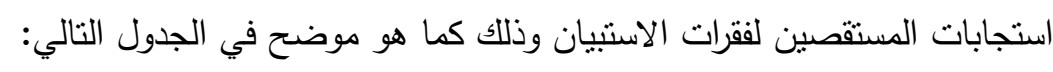

(ب) الشعـلِ: يحتوي على جميع جوانب محتوى البيانات الأساسية اللازمة للاراسة، وان يناسب مستويات عقلية منباينة للمبحوثين. 
(ج) التقنيـن: قام الباحث بتطبيق المقياس (الإستقصاء الإداري) على عينة كبيرة من مجتمع

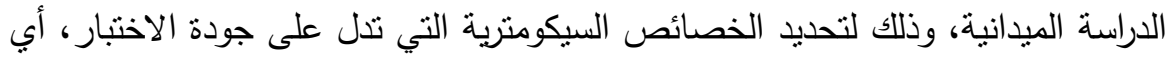
مدى توفر شروط الصدق والثبات والموضوعية والمعايير، وهذا ما سيتم توضيحه في في

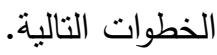

رابعاً / خطوات بناء المقياس (الإستقصاء الإداري): فيما يلي الخطوات التي اتبعها الباحث في بناء مقياس (الإسنقصاء الإداري):

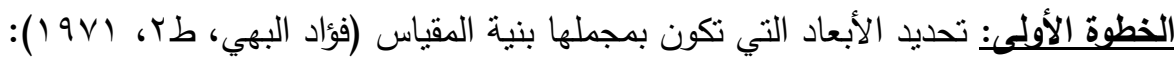

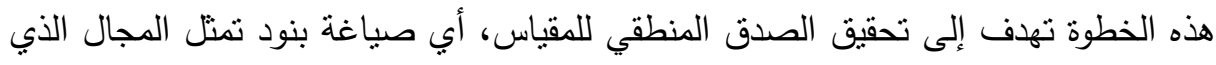

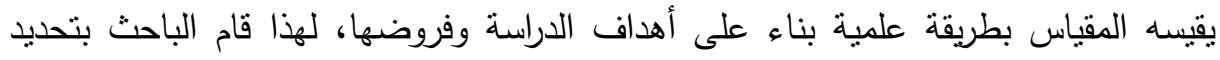
ستة أبعاد للمقياس وهي: • المعيار الأول (وضوح الروئية والنزام الإدارة العليا) كبعد أول. • • المعيار الثاني (دعم اللامركزية وبناء دوائر صنع القرار ) كبعد ثان.

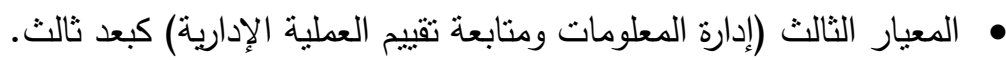
• المعيار الرابع (تفويض الإجراءات بالثقة وبناء الأمان والإسنقرار الوظيفي) كبعد رابع. • المعيار الخامس ( الإستتمار في التدريب والتطوبر والتحسين المستمر ) كبعد خامس. • المعيار السادس ( بناء الهوية المؤسسية المعتمد على تطبيق سته سيجما) كبعد سادس.

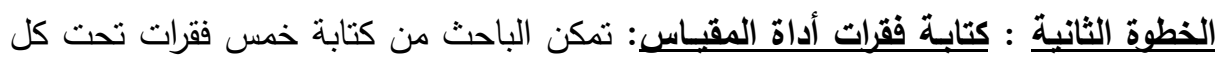
بعد من الأبعاد الستة، وبذلك يكون إجمالي عدد فقرات المقياس (الأستقصاء الإداري) هو ثلاثون فقرة، وقد اجتهد الباحث في الحرص على تكافؤ عدد الفقرات الزوجية والفردية، لأنه

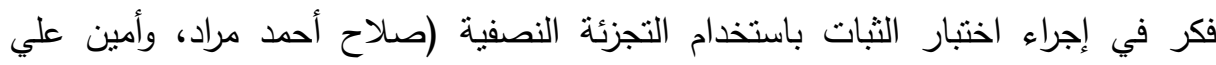

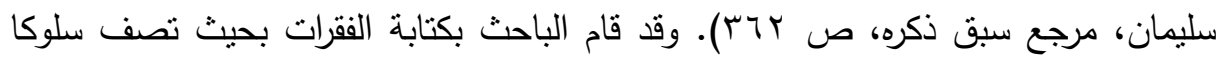
يرغب فيه المستجيب أو يتجنبه، أو يقوم به فعلا، أو يصف شعورا هورا اتجاه ممارسة إدارية يقوم

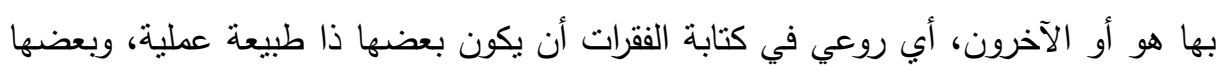
ذا طبيعة اجتماعية، وبعضها ذا طبيعة ذاتية. 


\section{مجتمع وعينة الاراسة:}

- اختار الباحث مجتمع المستهدفين من اللجان النوعية لمجلس الثعب المصري بإنباع أسلوب المسح الثامل في توزيع أداة الدراسة، بعد التحقق من صدقها وثباتها على لبن الستهدفين من مجتمع الدراسه، للمستهدفين من اللجان أو غيرهم من العناصر البرلمانية.

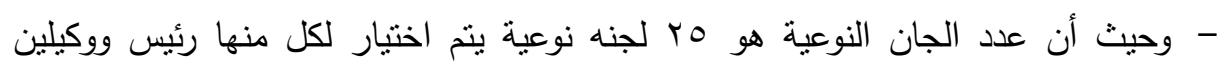
وأمين عام للجنه فقد قام الباحث بإختبار مجتمع المبحوثين بالثكل التالي مع تحديد

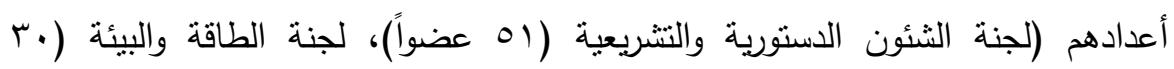

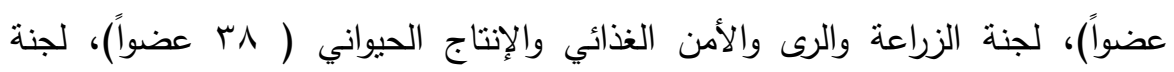

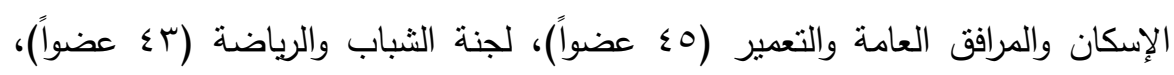

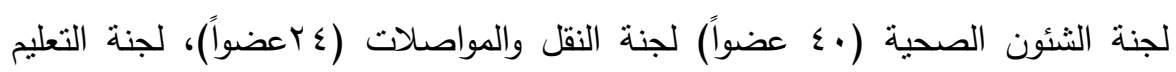

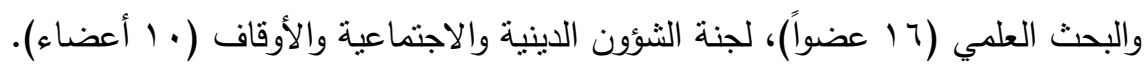

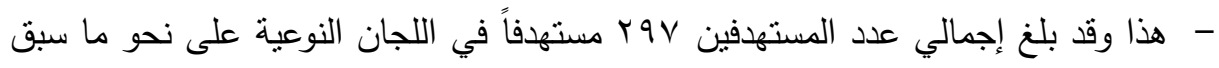

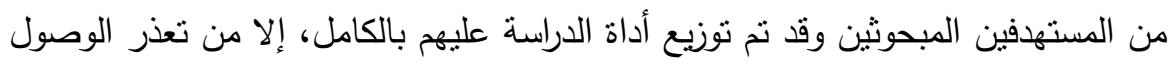

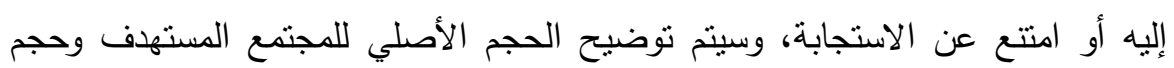

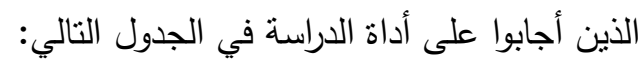

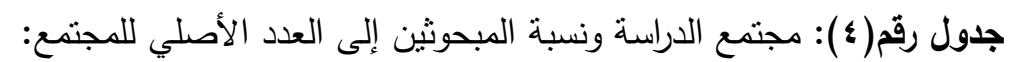

\begin{tabular}{|c|c|c|c|c|}
\hline نسبة & عدد المجنمع & المبحوثين & البيـــان & \\
\hline$\%$ \%।.. & 01 & 01 & لجنة الشئون الاستورية والتشريعية & \multirow{9}{*}{ 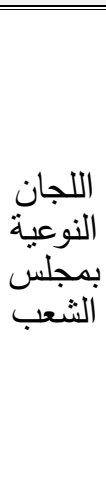 } \\
\hline$\% \vee \cdot$ & r. & YI & لجنة الطاقة والبيئة & \\
\hline $\begin{array}{c}\Lambda \varepsilon, Y \\
\%\end{array}$ & rᄉ & r & لجنة الزراعة والرى والأمن الغذائى & \\
\hline$\% \wedge$. & $\leqslant 0$ & $\bar{r}$ & لجنة الإسكان والمرافق العامة والتعمير & \\
\hline$\% 9$. & $\sum \Gamma$ & rq & لجنة الثباب والرياضة & \\
\hline$\% \wedge 0$ & $\varepsilon$. & rs & لجنة الشئون الصحصية & \\
\hline$\% \vee 0$ & rs & 11 & لجنة النقل والمواصلات & \\
\hline$\%$ Vo & 17 & TY & لجنة التعليم والبحث العلمي & \\
\hline$\% 1 \ldots$ & 1 . & 1. & لجنة الثؤون الدينية والاجتماعية & \\
\hline$\% \wedge \wedge$ & rqV & ror & المجمـــوع & \\
\hline
\end{tabular}


الصدق والثبات: قام الباحث بحساب معامل ثبات الذي هو نسبة التباين الحقيقي إلى التباين

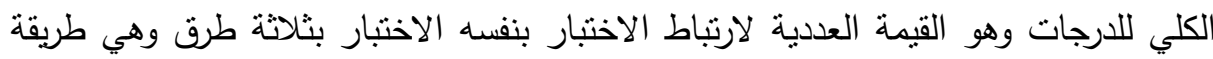

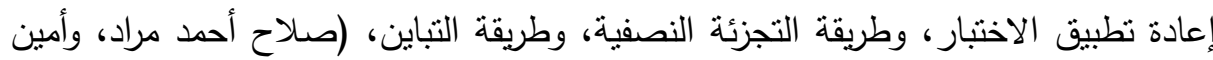

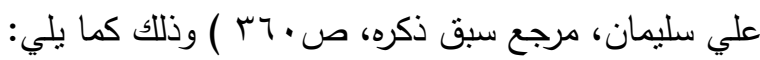

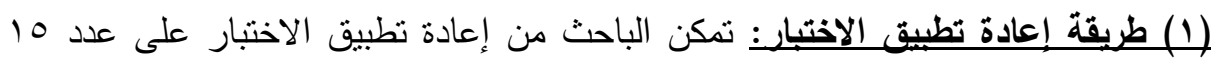

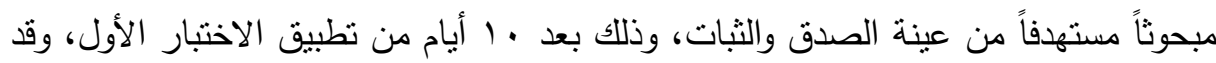

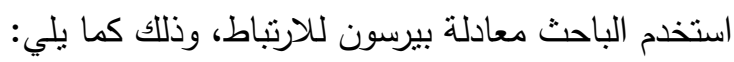

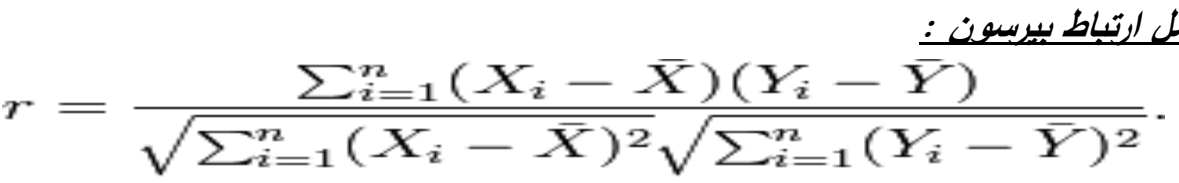

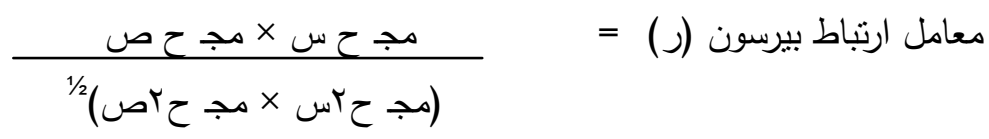

$$
\begin{aligned}
& \cdot \frac{, V \vee=\sum Y \wedge, q=}{1 / 2(0 Y 0, \vee \times O Q 1, \vee)}=
\end{aligned}
$$

وهذا يثير إلى أن معامل الثبات المحسوب جيد (VV, •)، وهو دليل على ثبات المقياس

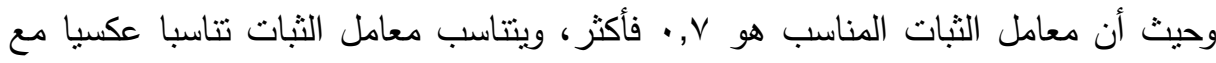

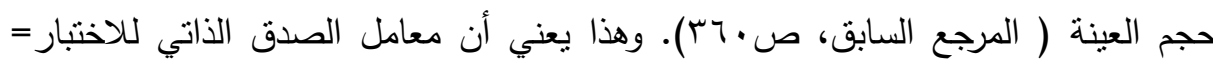

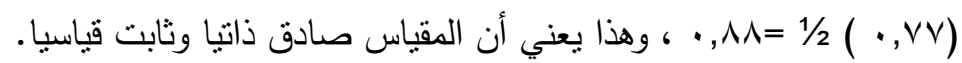

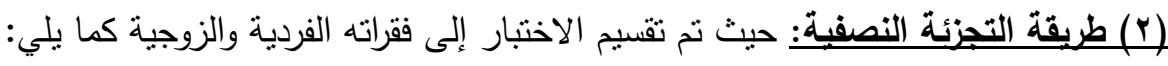

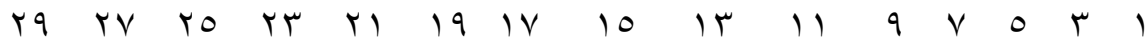

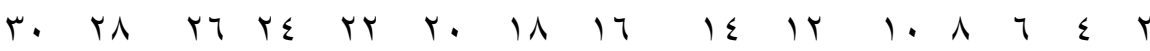
ثم استخدم الباحث درجات النصفين، في حساب معامل الارتباط بينهما، فنتج معامل Spearman ثبات نصف الاختبار ( 1/2r )، ويلي ذلك استخدام معادلة سبيرمان براون Brown 


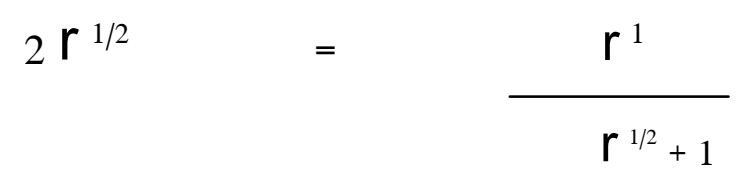

حيث أن ب: عدد أقسام الاختبار / / الاختبار

$$
\text { = }=\quad r^{1}
$$

وقد قام الباحث باستخراج هذا المعامل، باستخدام البرنامج الإحصائي SPSS، فوجده يساوي

$$
\cdot, 00=\frac{\cdot, r \Lambda \times r}{., r \Lambda+1}
$$

وهو معامل ثبات أقل من المعامل السابق حسابه، والسبب هو أن حجم عينة الاختبار

السابق (10 مبحوثا)، وهي أصغر من حجم عينة هذا الاختبار، التي كانت . ب مبحوثا.

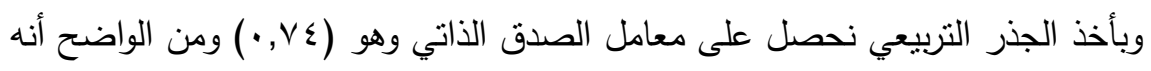
كلما انخفضت قيمة معامل الثبات انخفضت قيمة معامل الصدق الذاتي للمقياس.

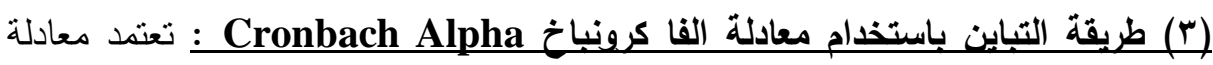

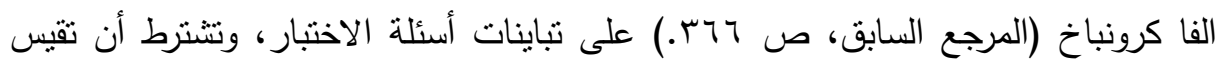
بنود الاختبار سمة واحدة فقط، ولذلك قام الباحث بحساب معامل الثبات لكل بعد على إنفراد،

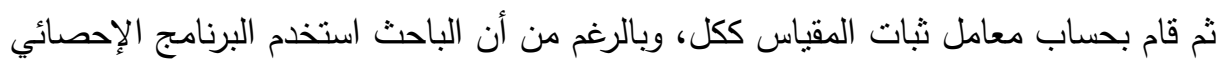

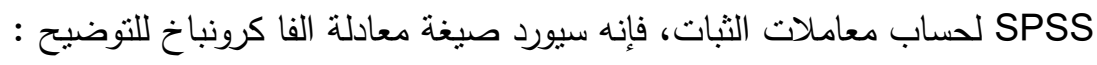

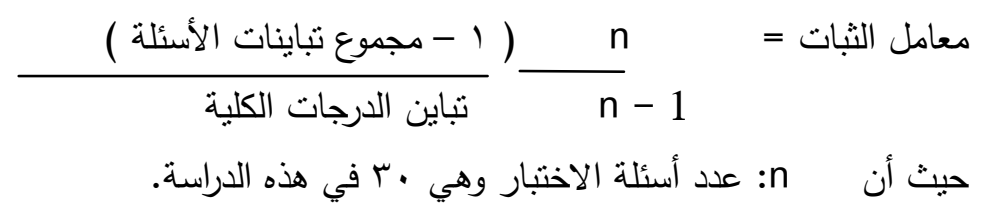


والجدول الآتي يوضح قيم معاملات ألفا كرونباخ لكل بعد على إنفراد وللمقياس ككل: جدول رقم(ه): معامل ثنات ألفا كرونباخ لأبعاد المقياس الرئيسة

\begin{tabular}{|c|c|c|c|}
\hline قيمة ألفا & لكلد بعدرات & الأبعـاد & \\
\hline$\cdot, \varepsilon V$ & 0 & وضوح الرؤية والنزام الإدارة العليا & 1 \\
\hline$\cdot, \mathrm{MT}$ & 0 & دعم اللامركزية وبناء دوائر صنع القرار & $r$ \\
\hline$\cdot, \Gamma$ & 0 & إدارة المعلومات ومتابعة تقييم العملية الإدارية & $r$ \\
\hline$\cdot, \Gamma$ & 0 & تفويض الإجراءات بالثقة وبناء الأمان والإستقرار الوظيفي & $\varepsilon$ \\
\hline$\cdot, r V$ & 0 & الإستثمار في التدريب والتطوير والتحسين المستمر & 0 \\
\hline 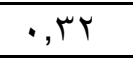 & 0 & بناء الهوية المؤسسية المعتمد على تطبيق منهجية سته سيجما & 7 \\
\hline ( & r. & الدرجة الكلية للمقياس & \\
\hline
\end{tabular}

تثير البيانات في الجدول رقم (0) إلى قيم معامل الثبات لإجابات المبحوثين، وتظهر

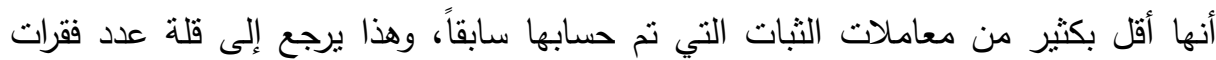

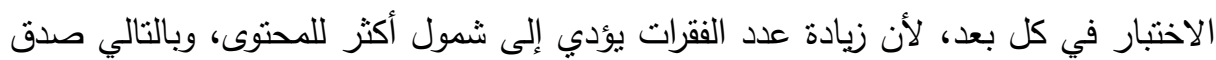

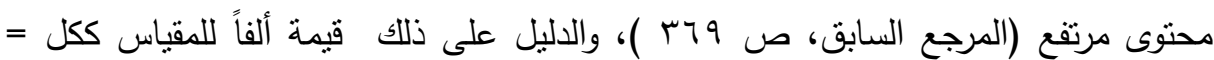
rآ, · ، حيث ارتفع عدد الفقرات من ه إلى • ب فقرة، وهي دلالة جيدة على صدق وثبات

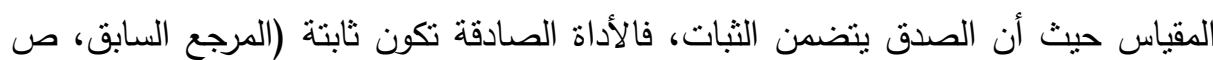
97\%). للتحقق من ثنات قائمة الإستقصاء قام الباحث باستخدام طريقة اعادة التطبيق لحساب معامل الثبات كما قام الباحث بحساب قيم الصدق الذاتي، ويمكن تلخيص اختبارات الصدق والثبات التي أجريت على العينة التي تم نطبيق مقياس (الإستقصاء الإداري) عليها في الجدول

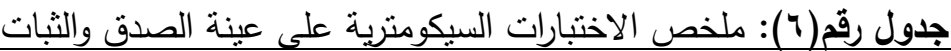

\begin{tabular}{|c|c|c|}
\hline الدلالة & الارجة & الاختتبار \\
\hline & & (ا) الصـــ \\
\hline عالية & اتفاق • ^ \% من المحكمين & (1) صدق المحتوى \\
\hline جيدة &., $0 \leqslant$ & (Y) الصدق التجريبي \\
\hline عالية & $\cdot, \wedge \wedge \ldots, \vee \vee \varepsilon$ & آ آ الصدق الذاتي \\
\hline & & (ب) الثبـات \\
\hline عالية & $\cdot, \mathrm{VV}$ & (1) معامل الثبات بطريقة إعادة تطبيق الاختبار \\
\hline جيدة &., 00 & (T) معامل النبات بطريقة التجزئة النصفية \\
\hline جيدة & $\cdot$ & ) معامل الفا كرونباخ \\
\hline
\end{tabular}


يستتتج مما سبق أن أداة الدراسة أوفت بالثروط السيكومنرية للاختبار الجيد، وأنها تفي

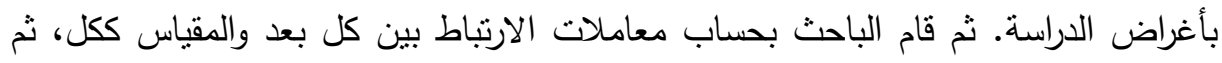

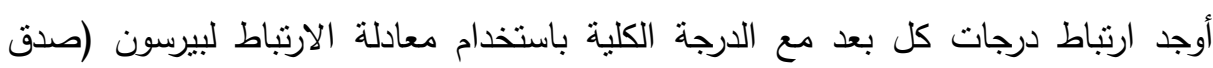

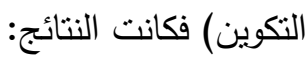
جدول رقم(V): معاملات الارتباط بين درجات أبعاد المقياس والدرجة الكلية للمقياس

\begin{tabular}{|c|c|c|}
\hline قيمة معامل الارتباط & الأبعـاد & \# \\
\hline$\cdot, \mathrm{V} \leqslant$ & وضوح الروئية والتزام الإدارة العليا & 1 \\
\hline$\cdot, \varepsilon \varepsilon$ & دعم اللامركزية وبناء دوائر صنع القرار & r \\
\hline$\cdot, 7 \pi$ & إدارة المعلومات ومتابعة تقييم العملية الإدارية & r \\
\hline$\cdot, \leqslant \mathrm{V}$ & تفويض الإجراءات بالنقة وبناء الأمان والإستقرار الوظيف & $\varepsilon$ \\
\hline., 00 & الإسنتمار في التدريب والتطوير والتحسين المستمر & 0 \\
\hline$\cdot, \varepsilon Y$ & بناء الهوية المؤسسية المعتدد على تطبيق منهجية سته سيجما & 7 \\
\hline
\end{tabular}

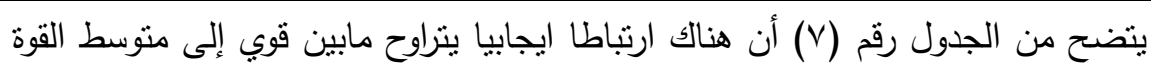

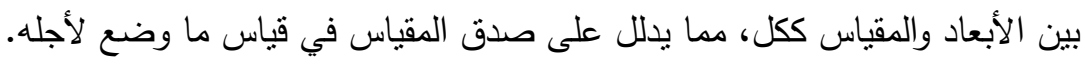
النتائج: وقد أنشارت نتائج الإستقصاء الإداري بالبيانات التالية:

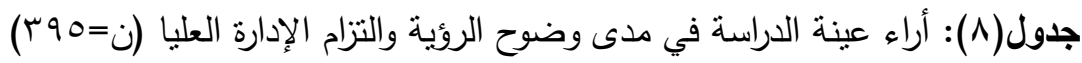

\begin{tabular}{|c|c|c|c|c|c|}
\hline الترتيب & الإتجاه & الإختلافل & الإلمعياري & المترجح & درجة الموافقة \\
\hline$r$ & 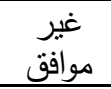 & Or,To & $1, r \cdot v$ & $r, \leqslant 0$ & 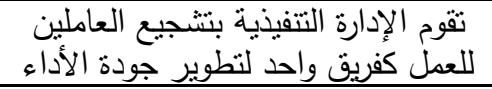 \\
\hline 1 & مبشدة & $r 7,07$ & $1,1 \times 9$ & $\varepsilon, Y_{0}$ & 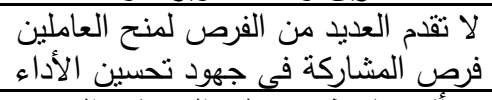 \\
\hline$\varepsilon$ & موافق & 00,77 & $1,1 \leq 1$ & $r, .0$ & 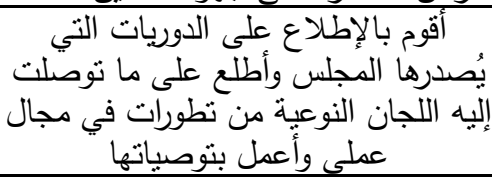 \\
\hline 0 & 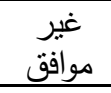 & 01,94 & $1, \cdot \leq 9$ & $r, \cdot r$ & 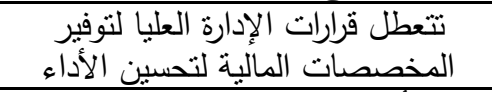 \\
\hline r & 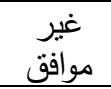 & س & I & Y,OV & تهنت أمانة المجلس بطرق إدية للنطور الإداري سيجما \\
\hline
\end{tabular}


كما هو مبين بالجدول السابق نجد أن عينة الدراسة قد اتجهت إجاباتهم بالإجابتين (غير موافق) و(غير موافق بشدة) لجميع العبارات عدا العبارة (لا نقدم العديد من الفرص لهند الهنح العاملين فرص المشاركة في جهود تحسين الأداء) أجابت عينه الدراسة عليه (موافق بشدة)

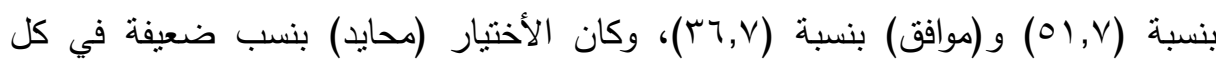

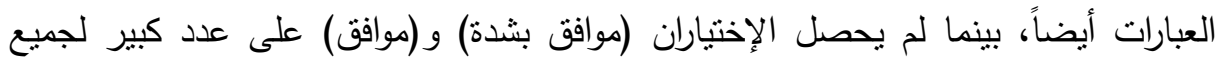

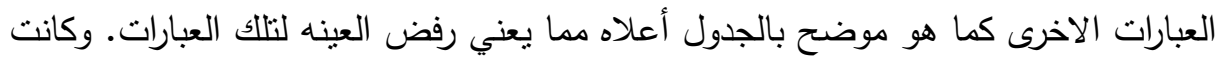

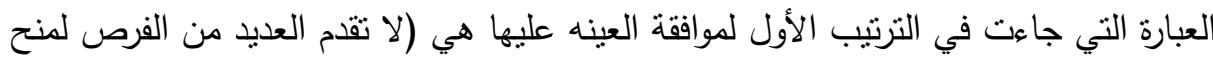

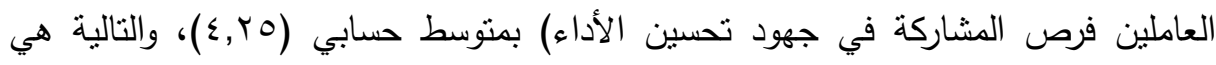

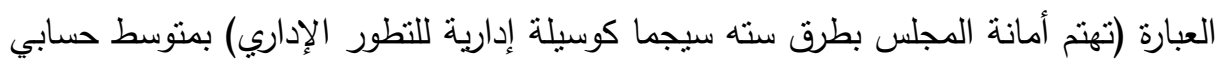

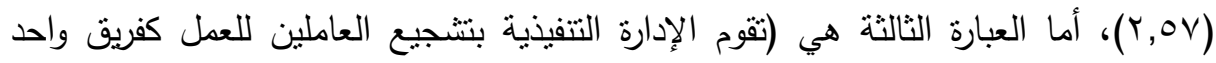

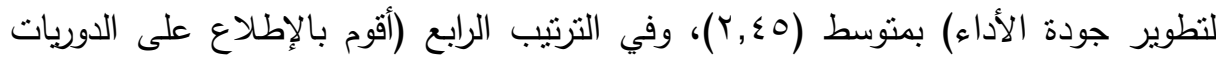

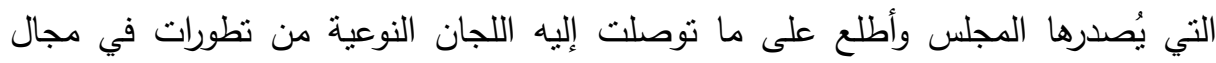
عملي وأعمل بتوصياتها) بمنوسط حسابي (Y.0. (Y)، وفي الترتيب الخامس (تتعطل قرارات

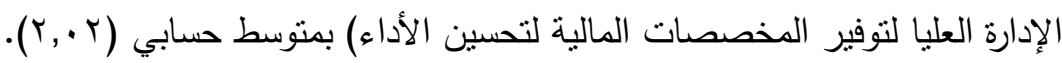

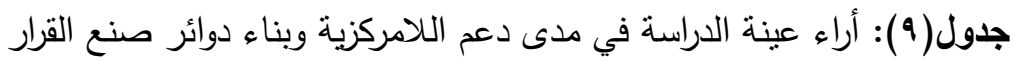

\begin{tabular}{|c|c|c|c|c|c|}
\hline الترتيب & الإتجاه & الإختلافل & الإلمعياري & المتوجط & درجة الموافقة \\
\hline 0 & 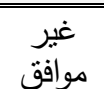 & $O \Lambda, Y Y$ & $1, r \backslash 1$ & $r, \cdot \wedge$ & بين أهداف أعضاء فريق العمل وأهدافهر الثخاك تعصارضية \\
\hline$r$ & 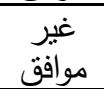 & $01, \mathrm{~V}$ & $1, r \cdot \Lambda$ & r,or & تدعم الإدارة فرص نطبيق في الأساليب الإدارية \\
\hline$\varepsilon$ & 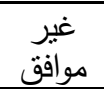 & 01,10 & 1,101 & Y,YY & 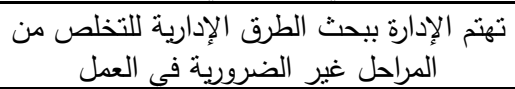 \\
\hline r & موافق & $r \Lambda, \cdot r$ & $1, I V Y$ & $\varepsilon, 1 \wedge$ & الإختصاصدات عاملاً سلبياً في صنم وضنع القرار \\
\hline 1 & موافق & $r Y, r \varepsilon$ & $\cdot, 970$ & E,TY & نحن كفريق عمل نتفهم بعضنا البعض ونفاغن ونعمل \\
\hline
\end{tabular}




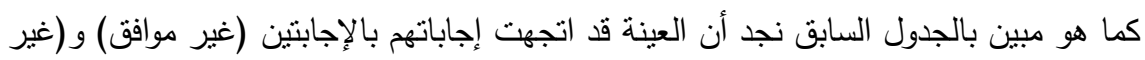
موافق بشدة) لمعظم العبارات عدا العبارتين (نحن كفريق عمل نتفهم بعضنا البعض ونعمل على الإنى

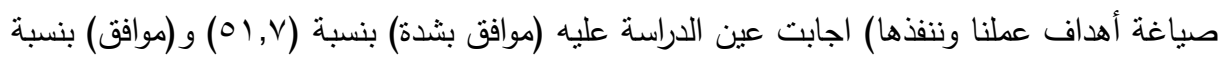
( (r,v)، وكذلك العبارة (تعد ضغوط العمل وعدم وضوح الإختصاصات عاملاً سلبياً في صنع القرار )

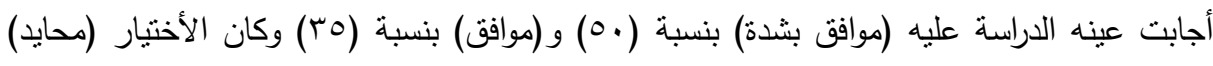

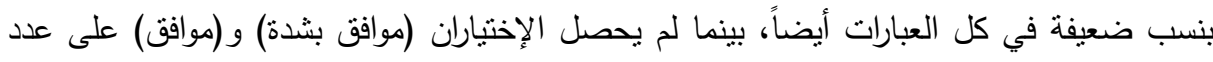

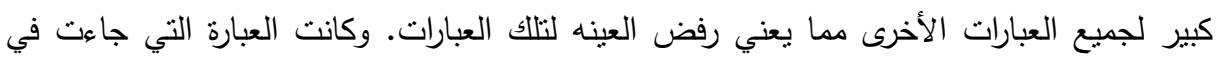

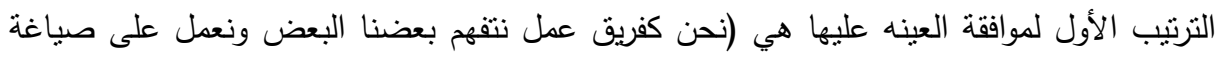

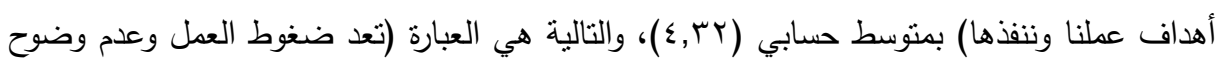

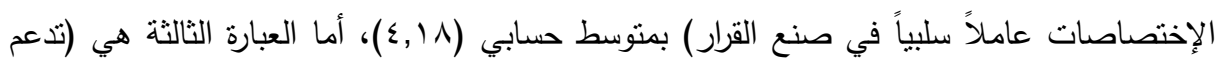

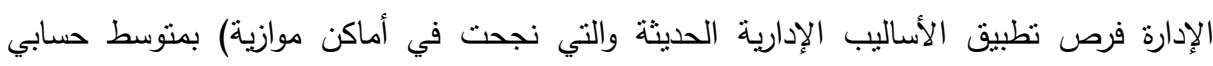

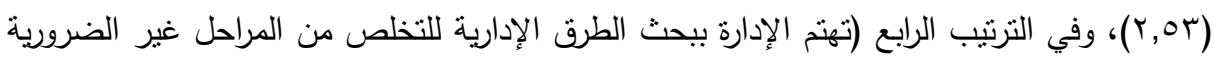

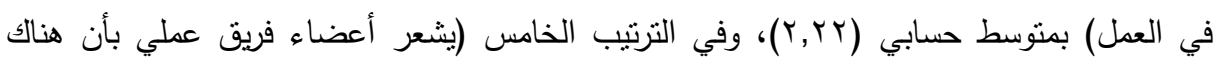

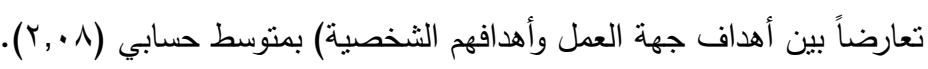
جدول( • (): نتائج الإحصاء الوصفي لعبارات إدارة نظم المعلومات ومتابعة تقييم العملية الإدارية

\begin{tabular}{|c|c|c|c|c|c|}
\hline الترتيب & الإتجاه & الإختلافل & الإمعرافي & المرجح & درجة الموافقة \\
\hline r & مبشدة & $\curlyvee \wedge, r \vee$ & 1,117 & $\varepsilon, 1 \wedge$ & لا أناقش وجهات نظري التِّي تتعارض \\
\hline$\varepsilon$ & 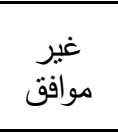 & $\varepsilon V, \cdot \varepsilon$ & $1,1 \leqslant r$ & $r, \varepsilon r$ & دقيقة لقياست الإدارة بإنتقاء أواختيار المتغير معايير \\
\hline 0 & 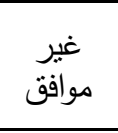 & $7 \cdot, 11$ & $1, r \wedge Y$ & $r, i r$ & 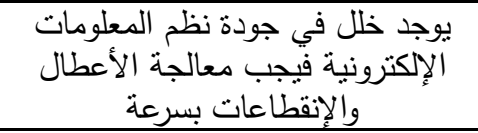 \\
\hline$r$ & موافق & $07, \leqslant 0$ & 1,rیr & $r, \leqslant 0$ & 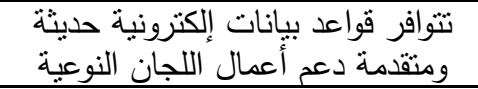 \\
\hline 1 & بشدة & $19, Y \wedge$ & - & $\varepsilon, \Gamma_{Y}$ & 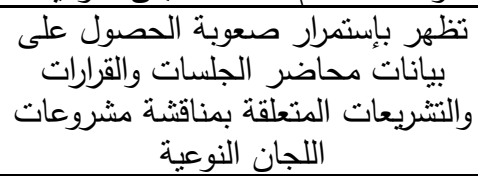 \\
\hline
\end{tabular}


كما هو مبين بالجدول السابق نجد أن عينة الدراسة قد اتجهت إجاباتهم بالإجابتين (غير

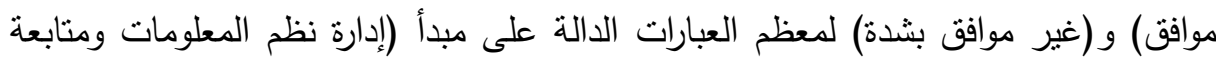

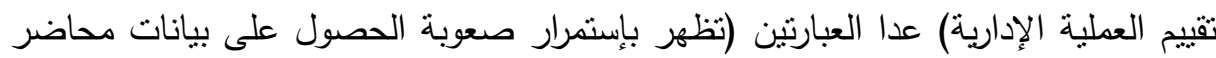

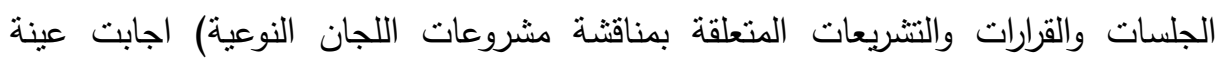

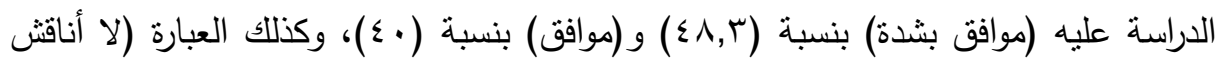

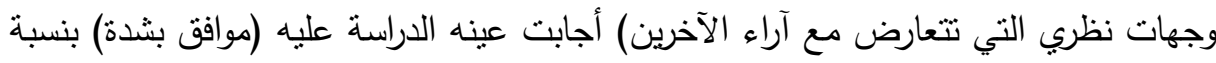

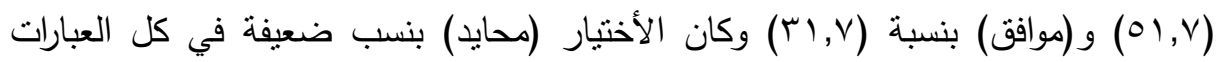
أيضاً، بينما لم يحصل الإختباران (موافق بشدة) و (موافق) على عدد كبير لجميع العبارات

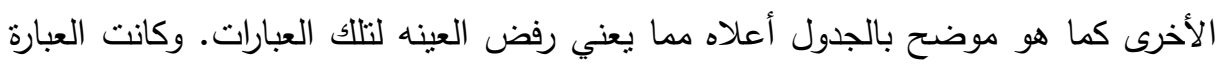
التي جاءت في الترتيب الأول لموافقة العينه عليها هي (تظهر بإستمرار صعوبة الحصول

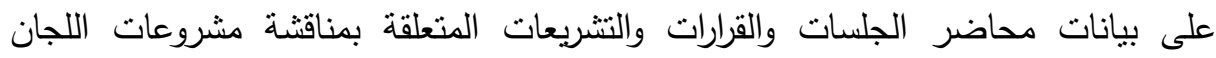

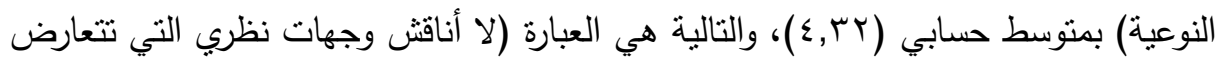

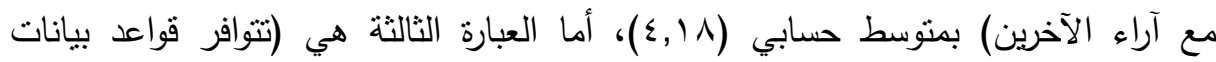

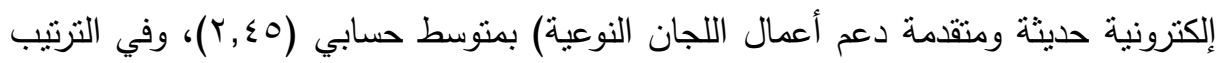

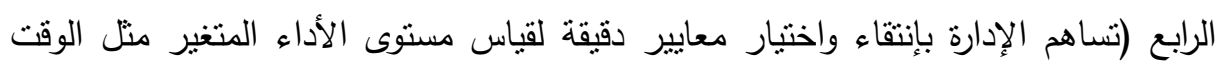

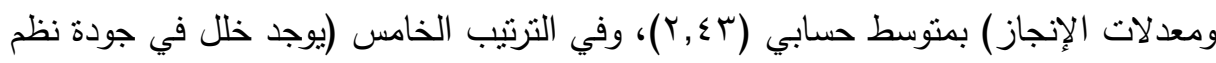

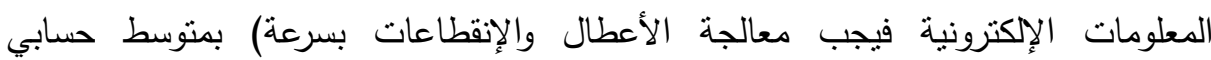


جدول(1 (1): أراء العينه في درجة تقويض الإجراءات بالثقة وبناء الأمان والإستقرار الوظيفي

\begin{tabular}{|c|c|c|c|c|c|}
\hline الترتيب & الإتجاه & الإختلامل & الألمعياري & المتوجط & درجة الموافقة \\
\hline 0 & 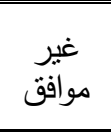 & Or,YI & $1,11 r$ & $r, 1 T$ & أعثتر أن روح العمل الزملاء في إنجاعي تجعلني \\
\hline r & 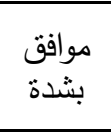 & YV,TY & $1,1 V \varepsilon$ & $\varepsilon, Y_{O}$ & 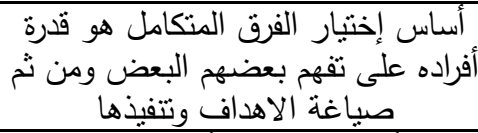 \\
\hline$r$ & موافيق & $0 \wedge,$. & אדצז, & $r, r_{0}$ & 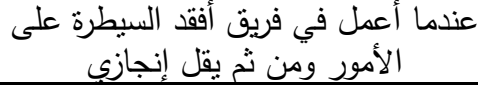 \\
\hline$\varepsilon$ & موافير & or, $\leqslant 0$ & $1,1 \vee 7$ & $r, Y$ & 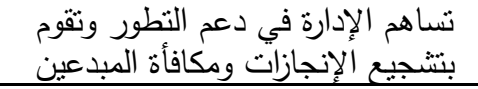 \\
\hline 1 & 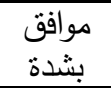 & $r_{0, \leqslant T}$ & $1, \cdot \wedge V$ & $\varepsilon, r V$ & الشعور بالهذوء والإستقرار الوظيفي يقل \\
\hline
\end{tabular}

كما هو مبين بالجدول السابق نجد أن عينة الدراسة قد اتجهت إجاباتهم بالإجابتين (غير

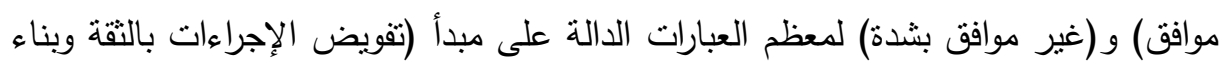

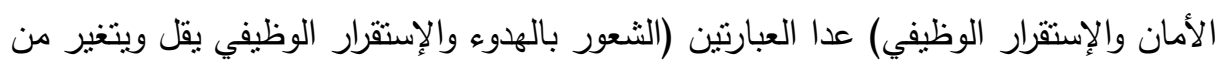

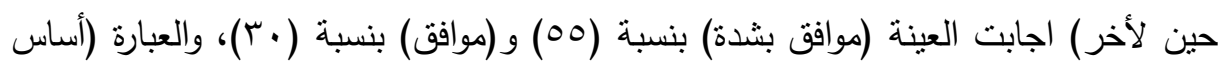

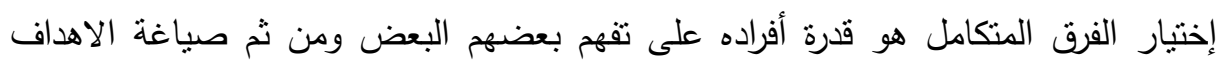

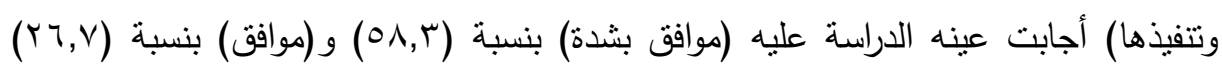
وكان الأختيار (محايد) بنسب ضعيفة في كل العبارات أيضاً، بينما لم يحصل الإختياران

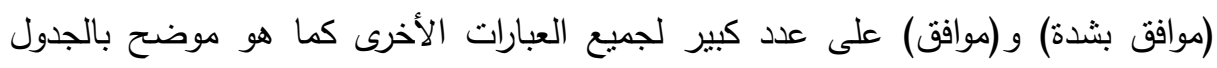

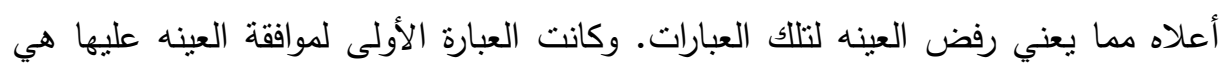
(الثعور بالهدوء والإستقرار الوظيفي يقل ويتغير من حين لأخر) اجابت عينة الدراسة عليه

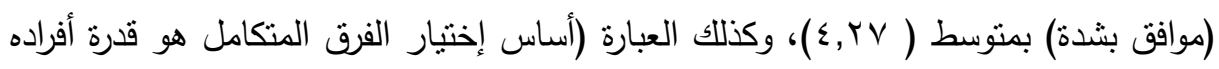

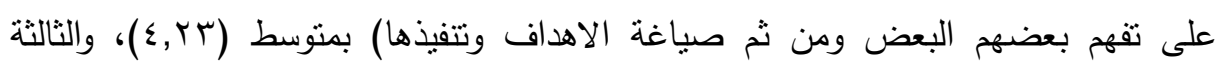

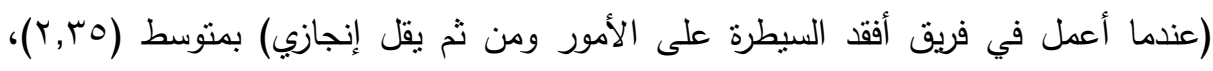

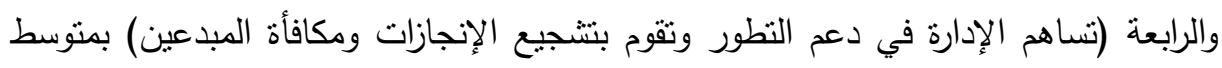


(Y,Y)، والخامسة (أعنقد أن روح العمل الجماعي تجعلني أكثر تعاوناً مع الزملاء في إنجاز

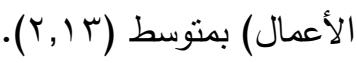

جدول(Y ( ): أراء عينه الدراسة على معيار الإستثمار في التدريب والتطوير والتحسين المستمر

\begin{tabular}{|c|c|c|c|c|c|}
\hline الترتيب & الإتجاه & الإختلاف معل & |الإنحراف & المثوسط المرجح & درجة الموافقة \\
\hline r & غير موافق & $07, V$ & $1, Y \wedge V$ & $r, Y V$ & أقوم بالإثترالك في الدورات التدريبية \\
\hline r & غير موافق & $O \Lambda, Y)$ & $1, \leqslant 7 V$ & Y,OY & الدمعقة الإدارة عمليات النطوير والبحوث الأداء وانجاز العمل \\
\hline 0 & غير موافق & $0 \leqslant, \Gamma \wedge$ & $1,1 \leq r$ & $1, \cdot r$ & 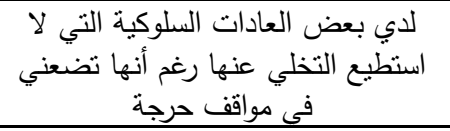 \\
\hline$\varepsilon$ & غير موافق & O\&, Or & $1,1 \leq 0$ & $r, 1$ & تحرص الإدارة على دعم القدرات \\
\hline 1 & موافق بشدة & גות & $1, r \cdot \Lambda$ & r,AV & 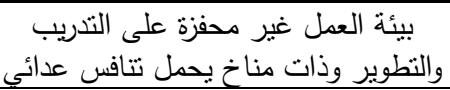 \\
\hline
\end{tabular}

كما هو مبين بالجدول السابق نجد أن عينة الدراسة قد اتجهت إجاباتهم بالإجابتين (غير موافق) و (غير موافق بشدة) لمعظم العبارات الدالة على مبدأ (الإستثمار في التدريب والتطوير والتحسين المستمر) عدا العبارة (بيئة العمل غير محفزة على التدريب والتطوير وذات مناخ

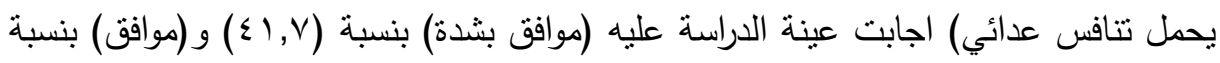
(M l,V) الإختياران (موافق بشدة) و (موافق) على عدد كبير لجميع العبارات الأخرى كما هو موضح بالجدول أعلاه مما يعني رفض العينه لتلك العبارات. وكانت العبارة الأولى لموافقة العينه

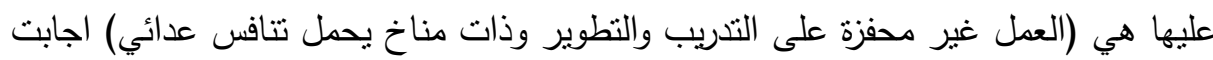
العينة (موافق بشدة) بمنوسط حسابي (r,AV)، وكذللك العبارة (تدعم الإدارة عمليات التطوير والبحوث المتعلقة برفع مستوى الأداء وإنجاز العمل) بمتوسط حسابي (Y,Or.Or)، أما الثالثة

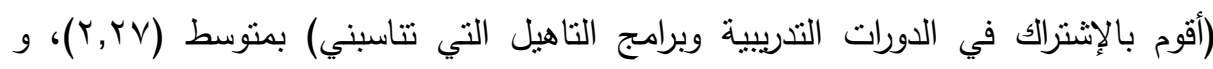

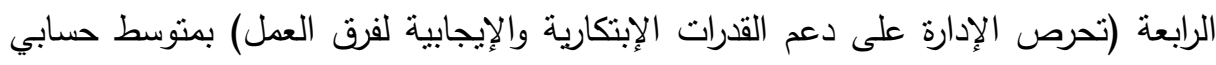
(Y,I)، والخامسة (لدي بعض العادات السلوكية التي لا استطيع التخلي عنها رغم أنها 
تضعني في مواقف حرجة) بمتوسط (r . , (). وقد لاحظ الباحث أن عينه الدراسة قد اتجهت

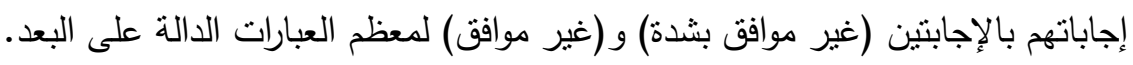
جدول(r I ): معيار بناء الهوية المؤسسية بتطبيق معايير الجودة (سته سيجما) مثالاً

\begin{tabular}{|c|c|c|c|c|c|}
\hline الترتيب & الإتجاه & الإختلاف & الإلمعياري & المتوسط & درجة المواققة \\
\hline 0 & موافقير & $\cdot, 07$ & $1,1 \mathrm{r}$ & r & درجة الرضا الوظيفي والنفسي مرتفعة \\
\hline$\varepsilon$ & 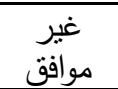 & $\varepsilon \vee, V$ & $1, .17$ & r,IT & 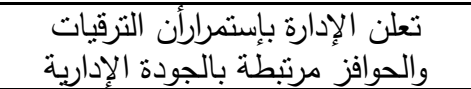 \\
\hline 1 & 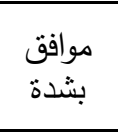 & $r \varepsilon, q \Gamma$ & $1, \varepsilon r q$ & $\varepsilon, 1 Y$ & 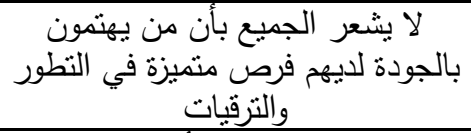 \\
\hline$r$ & 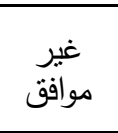 & Or, $\cdot \varepsilon$ & $1,19 \mathrm{~V}$ & r,r & 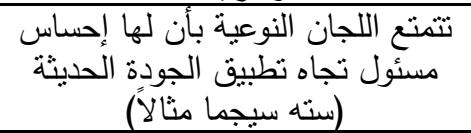 \\
\hline r & موافق & $00, T_{T}$ & $1, r V Y$ & $r, \varepsilon \wedge$ & بالجودة أساس القيادة لإثبات أن النتاح التزامهاية \\
\hline
\end{tabular}

كما هو مبين بالجدول السابق نجد أن عينة الدراسة قد اتجهت إجاباتهم بالإجابتين (غير هوناتئ

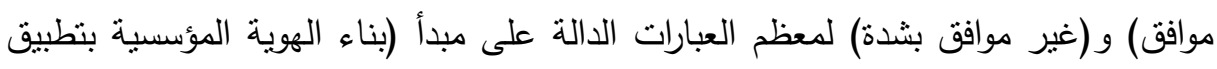

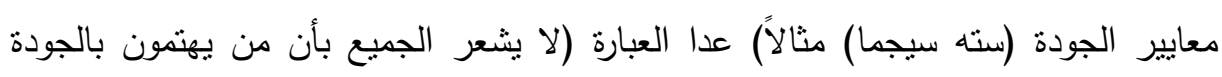

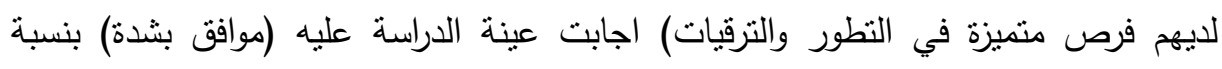
(O I, V)

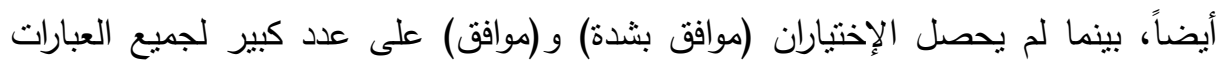

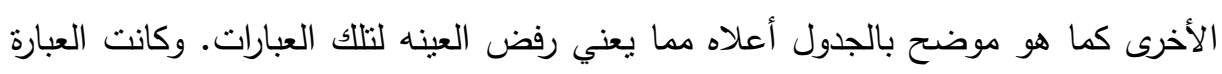
التي جاءت في الترنيب الأول لموافقة العينه عليها هي (لا يشعر الجميع بأن من يهتمون بالجودة لديهم فرص متميزة في التطور والترقيات) اجابت عينة الدراسة عليه (موافق بشدة)

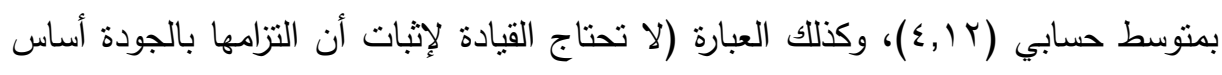

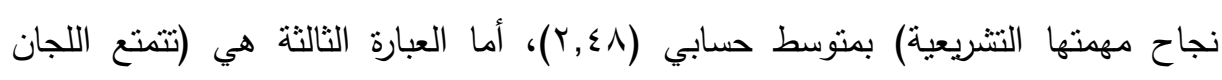

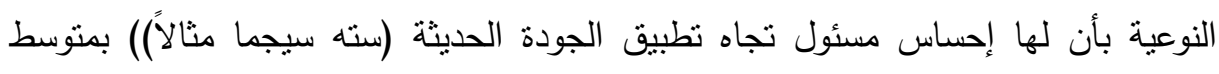

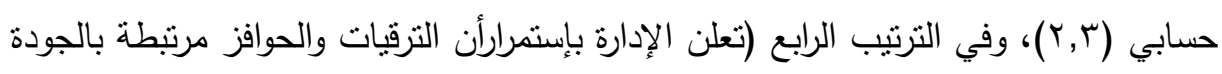


الإدارية) بمتوسط حسابي (Y,I)، وفي الترتيب الخامس (درجة الرضا الوظيفي والنفسي

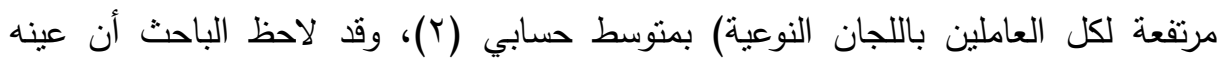

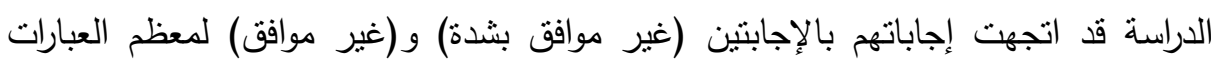

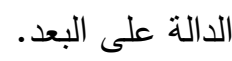

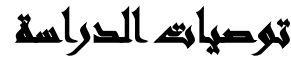

- يرى الباحث أهية بتأهيل الموارد البشرية الجديدة ووضع خطة لتوزيع الصلاحيات المركزية وتأهيل بعض المدربين الداخليين وانشاء جائزة وطنية بإسم مجلس الثعب وانشئ وانشاء جائزة داخلية لحفز العاملين بالمجلس لهصن

- الإهتمام المستمر بعقد اجتماع دوري بين أعضاء اللجنة من النواب مع مراعات منهجية باتهات

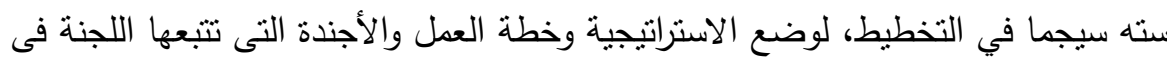

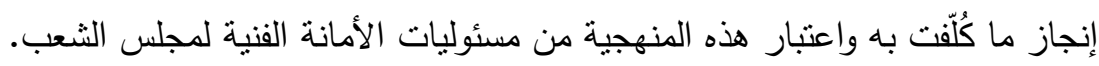

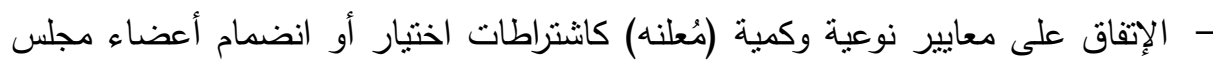

الثعب للجان النوعية المتخصصة ومنها اجتياز برنامج تعريفي بمنهجية سته سيجما.

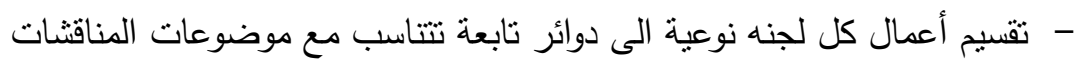

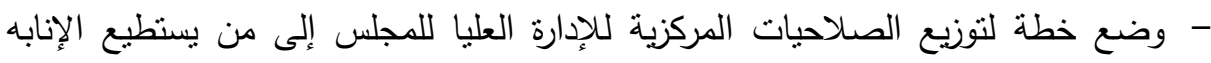
عنها - تفعيل مركز التدريب الداخلي لوضع خطط تدريب تراكمية بهذف التدريب على استثمار منهجية سته سيجما كنموذج جودة إداري تكون إدارة التدريب بالمجلس مسئولة عنها. - تأهيل بعض المدربين الداخليين من موظفي المجلس ليقوموا بالتدريب الداخلي على تطبيق بلهي

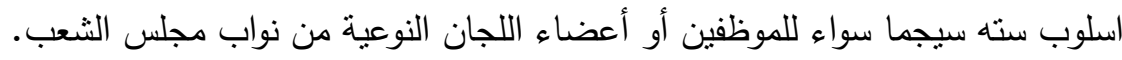

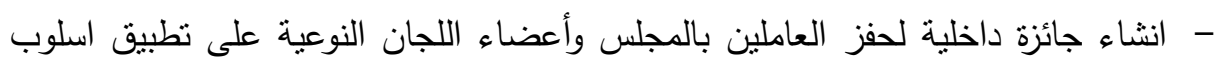


- تدريب الكادر الإداري بالمجلس على متابعة نظم المعلومات البيئي باستخدام منهجية سته سيجما وتكون وحدة تكنولوجيا المعلومات الثلى داخل المجلس هي المسئولة عن المتابعة والتقنين.

\section{المرالم:}

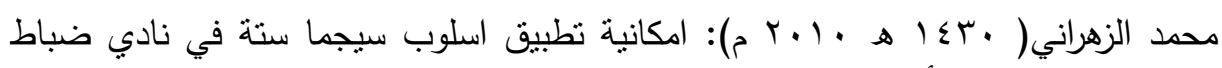

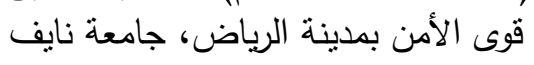

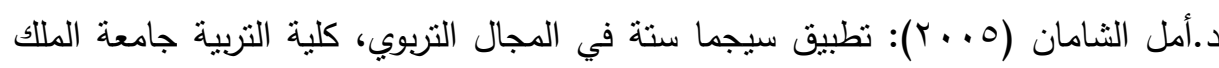
سعود (م)

كنعان ونواف(0 . ـrم): اتخاذ القرارات التنظيمية بين النظرية والتطبيق، دار النشر عمان الأردن

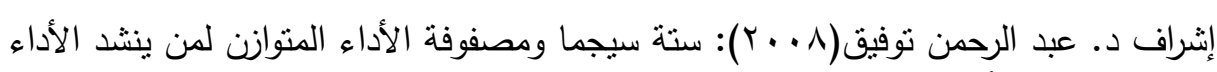
الأمنل، مركز الخبرات المهنية للإدارة

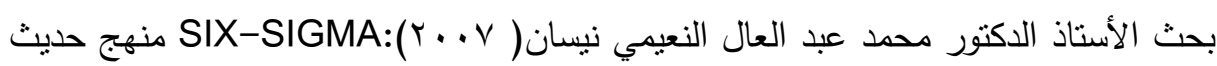

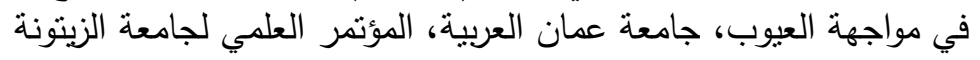

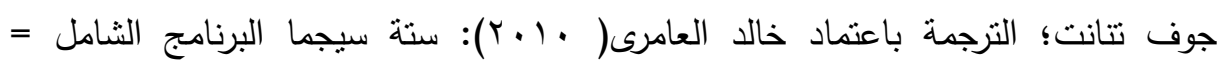
Design for six sigma

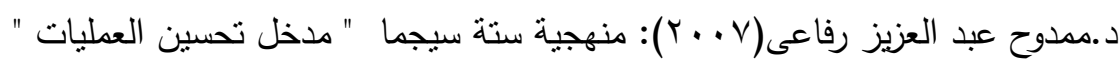

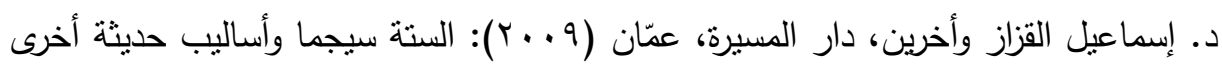
في إدارة الجودة الثاملة

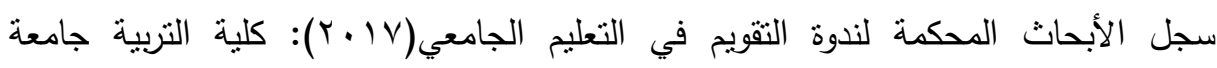

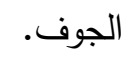

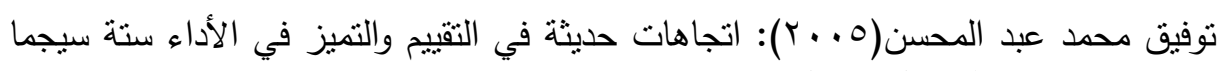
وبطاقة القياس المتوازن

د.يونان لبيب رزق (199 (م): قصة البرلمان المصري، مؤسسة دار الهلال للطبع والنشر.

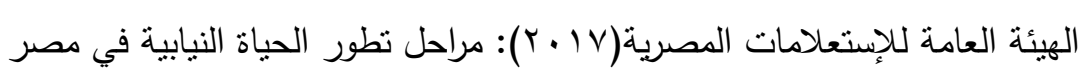

T.Keller, (2010): The Six Sigma handbook, 3ed, Pyzdek, Mc GrawHill

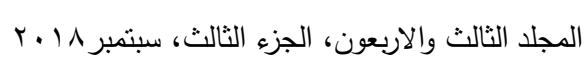


Sung H. Park,(2003): Six Sigma for Quality and Productivity Promotion, Published by the Asian Productivity Organization, Japan.

Stephan Lunau (2009): Design for Six Sigma+Lean ToolsetSpringerUSA.

George Ecke,(2003): Six Sigma for Everyone, John Wiley \& Sons,Inc.‘. Jaap van den Heuvel,(2006): The Effectiveness of ISO 9001 and Six Sigma in Healthcare, Beaumont Quality Publications

Anand M. Joglekar,(2003): Statistical Methods for Six Sigma In R\&D and Manufacturing, A JOHN WILEY \& SONS, INC., PUBLICATION.

Stephen A. Zinkgraf, (2006): Six Sigma:The First 90 Days,Prentice Hall.

Thomas Pyzdek\& Paul A. Keller,(2010, 2003, 2001): Six Sigma Handbook, Third Edition, by The McGraw-Hill Companies, Inc

Thomas MacCarty(2004): The Six Sigma Black Belt Handbook, The McGraw-Hill Companies 
نزار كمال محمد نصري المحلاوي وآخرون

\title{
THE REQUIREMENTS OF APPLYING THE SIX \\ SIGMA METHOD TO DEVELOP ADMINISTRATIVE \\ WORK IN THE DISCUSSION OF PROJECTS WITHIN \\ THE SPECIFIC COMMITTEES OF THE EGYPTIAN \\ HOUSE OF REPRESENTATIVES
}

\begin{abstract}
Mohamed, N. K. ${ }^{(1)}$; Tolba, A. ${ }^{(2)}$ and Wahdan, M. ${ }^{(2)}$
1) Institute of Environmental Studies and Research, Ain Shams University. 2) Faculty of Commerce, Ain Shams University
\end{abstract}

\begin{abstract}
Humanity has defined many quality management systems which have been associated with the civilizational and administrative development of the peoples. Recently, there has been a need to activate the wheel of production and to focus a lot of attention to the development of all administrative aspects. The research focuses on clarifying the requirements of applying Six Sigma method to develop administrative work which responsible to the process of discussing projects within the specific committees of the Egyptian House of Representatives.

The objective of the research was to identify the dimensions of the quality of the administrative process within the Specialized Committees (qualitative) by identifying (visibility and commitment of senior management, supporting decentralization and building decision-making circles, managing information and monitoring the evaluation of the administrative process, Accreditation of trust procedures, building safety and job stability, investing in training, development and continuous improvement, building institutional identity by applying quality standards using the Six Sigma methodology). The analytical descriptive approach was used to form the theoretical framework for the research. The data were collected through a survey questionnaire as a
\end{abstract}

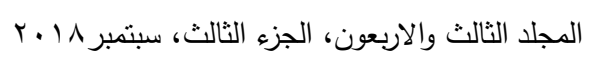


main tool for research through a sample of 297 parliamentary members involved in the administrative processes of the People's Committees of the Egyptian House of Representatives. The results show weakness in the decision-making procedures. Therefore, Administrative steps to support decentralization and build decision-making circles and so the study recommended the rehabilitation and training for the human resources also the development of a plan for the distribution of central powers and the rehabilitation of some internal trainers and establishment of a national award under the name of the Egyptian House of Representatives. 